\title{
Anti-dengue Vaccines: From Development to Clinical Trials
}

\author{
Josilene Ramos Pinheiro-Michelsen 1,2, Rayane da Silva Oliveira Souza ${ }^{1}$, \\ Itana Vivian Rocha Santana ${ }^{1}$, Patrícia de Souza da Silva ${ }^{1,2}$, Erick Carvalho Mendez ${ }^{2}$, \\ Wilson Barros Luiz ${ }^{2}$ and Jaime Henrique Amorim ${ }^{1,2 *}$

\begin{abstract}
1 Laboratório de Agentes Infecciosos e Vetores, Centro das Ciências Biológicas e da Saúde, Universidade Federal do Oeste da Bahia, Barreiras, Brazil, ${ }^{2}$ Programa de Pós-graduação em Biologia e Biotecnologia de Microrganismos, Universidade Estadual de Santa Cruz, Barreiras, Brazil
\end{abstract}

Dengue Virus (DENV) is an arbovirus (arthropod-borne virus). Four serotypes of DENV are responsible for the infectious disease called dengue that annually affects nearly 400 million people worldwide. Although there is only one vaccine formulation licensed for use in humans, there are other vaccine formulations under development that apply different strategies. In this review, we present information about anti-dengue vaccine formulations regarding development, pre-clinical tests, and clinical trials. The improvement in vaccine development against dengue is much needed, but it should be considered that the correlate of protection is still uncertain. Neutralizing antibodies have been proposed as a correlate of protection, but this ignores the key role of T-cell mediated immunity in controlling DENV infection. It is important to confirm the accurate correlate of protection against DENV infection, and also to have other anti-dengue vaccine formulations licensed for use.

Keywords: dengue, vaccine development, pre-clinical tests, clinical trials, countries

\section{INTRODUCTION}

Dengue Virus (DENV) is an arbovirus (arthropod-borne virus) transmitted to humans by mosquitoes of the Aedes genus (1). There are four serotypes of DENV (DENV1-4) that belong to Flavivirus genus of the Flaviviridae family. These are enveloped viruses with an icosahedral capsid and a genome composed of single stranded RNA of positive polarity, which encodes a single polyprotein that gives rise to three structural proteins (C, capsid; prM, membrane; E, envelope) and seven non-structural proteins: NS1, NS2A, NS2B, NS3, NS4A, NS4B, and NS5 (2). The four serotypes of DENV cause a disease called dengue (3) that annually affects nearly 400 million people worldwide (4). Dengue is a fast growing public health problem caused by many factors such as increased urbanization, population growth, increasing migration, and international travel, as well as the difficulties of effective vector control. Together, these factors contribute to the spread of the disease (5).

The World Health Organization (WHO) has highlighted the development of a safe and effective vaccine against the four serotypes of DENV as a priority. However, the vaccine development is challenging because of a limited understanding of the viral pathogenesis. A pathological phenomenon known as antibody-dependent enhancement (ADE) is well-reported in literature. Antibodies generated in response to a first infection by a specific serotype are able to recognize another serotype at a second infection. However, they are not specific and, therefore, neutralization 
of viral particles is not effective. The antigen-antibody complex is recognized by $\mathrm{Fc}-\gamma$ receptors-bearing phagocytic cells, which facilitates viral entry and provides an enhanced replicative capacity for the virus (2).

There are currently six vaccine formulations at different stages of development with only one licensed for use. Most of these vaccines are primarily based on the envelope proteins prM and $\mathrm{E}$, which are believed to induce protective immune responses in humans (6-9). However, it is very important to consider that the human immune response to DENV is dominated by highly crossreactive antibodies endowed with neutralizing and enhancing activity $(8,10)$. This leads us to question the importance of epitopes contained in envelope proteins with regard to the generation of a protective immune response (11). Another very important point to note in the development of anti-dengue vaccines, especially attenuated tetravalent live vaccines, is that the replication of all four DENV serotypes must be balanced, as dominant epitopes may interfere with replication of nondominant serotypes. This phenomenon may result in preferential antibody response to dominant strains, which could lead to a severe disease on dengue challenge (12).

In this review, we present information regarding the development, preclinical and clinical trials of anti-dengue vaccine formulations. We included only vaccine formulations with at least one published result of clinical trial. Positive and negative points of vaccine formulations discussed in the text are presented in Table 1. In addition, phase I, II, and III clinical trials that have been carried out in several endemic and non-endemic countries worldwide are indicated in the map (Figure 1).

\section{MAIN BODY \\ Dengvaxia $^{\circledR}$}

The anti-dengue vaccine of Sanofi Pasteur is a live, attenuated, and tetravalent recombinant vaccine called ChimeriVax ${ }^{\mathrm{TM}}$, Dengvaxia $^{\circledR}$ or CYD-TDV (Chimeric yellow fever-denguetetravalent dengue vaccine)-here, vaccine's names will be used according to the history of vaccine development, as shown in Table 2. It was initially developed by the National Institutes of Health (NIH) and the University of St. Louis $(74,75)$. The vaccine formulation consists of chimeric viruses constructed by using infectious clone technology. Genomic sequences encoding the pre-membrane (prM) protein and the envelope glycoprotein (E) of the 17D strain of Yellow fever virus (YFV) were replaced by those of each of the four serotypes of DENV (76) (Figures 2A,B). The 17D strain of YFV has been used for more than 6 decades as a vaccine. It was selected as a backbone for chimerization because of its safety, rapid onset and duration of immunity (77). The DENV strains used in the construction of chimeras were: DENV1 PUO359 strain, isolated in Thailand in 1980, and named ChimeriVax-D1; DENV2 PUO-218 strain, isolated from a child during the 1980 epidemic in Bangkok, and named ChimeriVaxD2; DENV3 strain PaH881/88, isolated in Thailand in 1988, and named ChimeriVax-D3; and DENV4 1228 strain, isolated in 1978 in Indonesia, and named ChimeriVax-D4 (77-79).

Reports of development of monovalent vaccine formulations were published in 2000 (77) for DENV2 and in 2001 for
DENV1, DENV3, and DENV4 (78). In preclinical studies, ChimeriVax $^{\mathrm{TM}}$ viruses were shown to have similar growth with regard to wild-type DENV, as evaluated in human myeloid dendritic cells (DCs) and in three hepatic cell lines (HepG2, Huh7, and THLE-3). In contrast with YFV 17D strain, chimeric viruses were shown to be non-hepatotropic, as shown by their lack of growth in human liver cells (80). In addition, ChimeriVax viruses were shown to be highly attenuated for Aedes albopictus and Aedes aegypti mosquitoes in terms of infection and dissemination (81). Moreover, non-human primates (NHP) were shown to develop protective humoral immune response after a single dose immunization regimen capable of controlling levels of viremia (76). Importantly, chimeric viruses were shown to be non-neurovirulent in mice and lead to viremia at similar levels of the YFV $17 \mathrm{D}$ vaccine strain in NHP (78).

Clinical trials with the vaccine were carried out in North and South America, Asia, and Oceania (see Figure 1), in order to cover populations with different flavivirus infections and vaccination histories (13). Trials of phase I, II, and III involved more than 40,000 volunteers from 16 countries (see Table 1) and evaluated safety, immunogenicity, and protective efficacy. ChimeriVax ${ }^{\mathrm{TM}}$-DEN2 presented a safety level similar

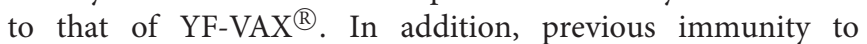
YFV did not interfere with ChimeriVax ${ }^{\mathrm{TM}}$-DEN2 immunization and a long-lasting immunity with high serum levels of cross-neutralizing antibodies was observed to all four DENV serotypes after immunization (82). In Mexico, the tetravalent vaccine was subjected to a phase I clinical trial based on an immunization regimen of three doses given in children and adults. The vaccine formulation, named at that time as TDV (tetravalent dengue vaccine), was shown to be safe and capable of eliciting a neutralizing antibody response against the four serotypes of DENV (83). In another phase I trial with flavivirus-naive adults, seroconversion to DENV1 in a two-dose regimen was lower (92\%) compared to a regimen based on three doses, which reached $100 \%$ seroconversion to all serotypes of DENV (84). In Philippines, immunogenicity was compared in immunization regimens of two or three doses, and $85 \%$ of the volunteers seroconverted to all DENV serotypes, regardless of the immunization regimen (85). The safety and immunogenicity profiles of TDV continued to be evaluated in phase II trials.

The vaccination induced a neutralizing antibody response against all DENV serotypes and was well-tolerated in children and adolescents in phase II trials carried out in Brazil (14) and in Colombia, Honduras, Mexico, and Puerto Rico (15). Relevantly, it was shown that prior exposure to YFV or monovalent dengue vaccines does not produce adverse effects or any other safety issues. Conversely, such prior exposure contributes to an increased immunogenicity of the vaccine formulation (16). Moreover, a three-dose regimen had a good safety profile in 211 years old Peruvian children with a history of YFV vaccination and elicited robust antibody responses that were balanced against the four DENV serotypes (17). Other phase II clinical trials supported the evaluation of the vaccine formulation (named as CYD-TDV at that time) under phase IIb as well as phase III trials 
TABLE 1 | Pros and cons of the seven anti-dengue vaccines registered at ClinicalTrials.gov (accessed until March 31, 2020).

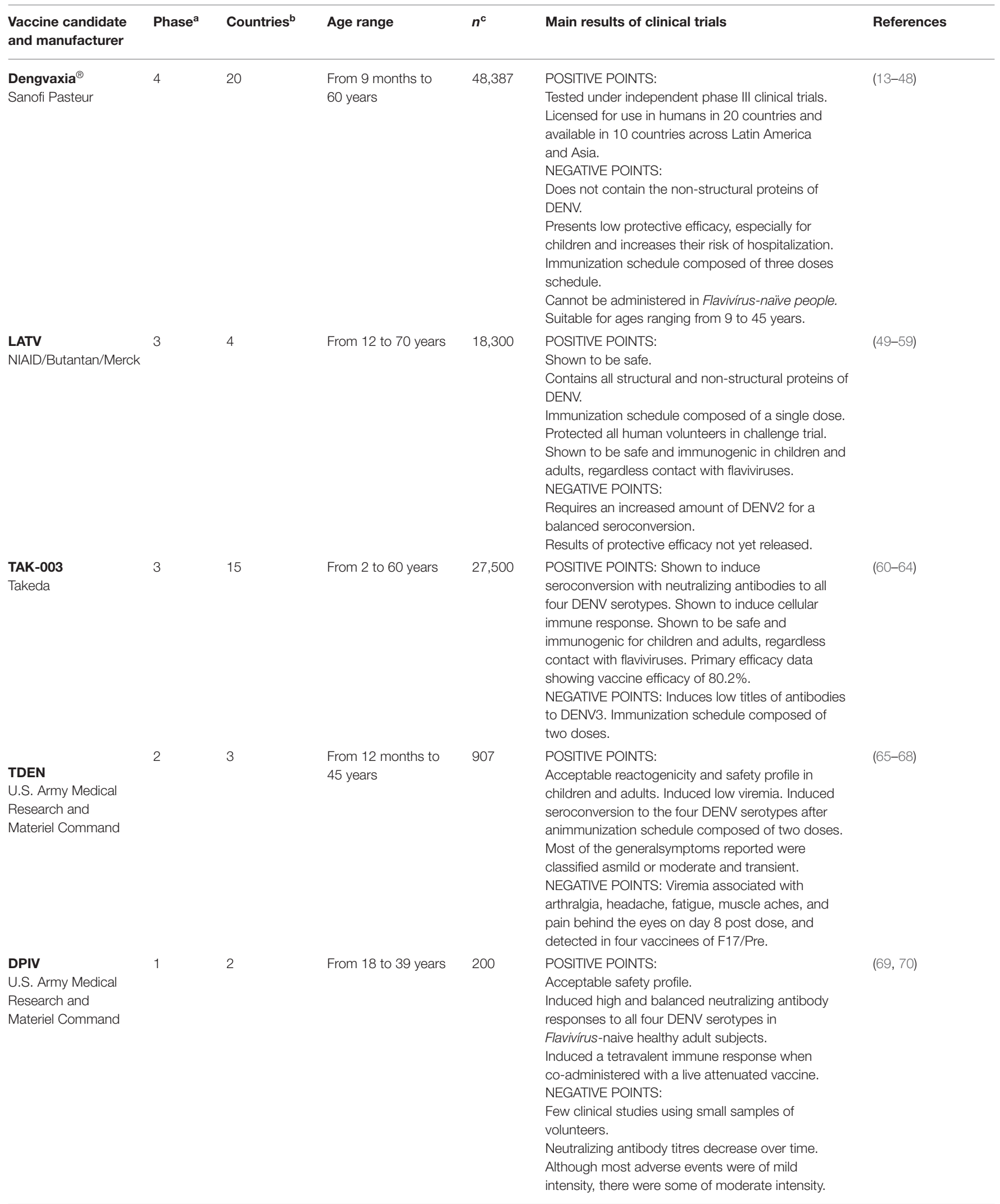


TABLE 1 | Continued

\begin{tabular}{|c|c|c|c|c|c|c|}
\hline $\begin{array}{l}\text { Vaccine candidate } \\
\text { and manufacturer }\end{array}$ & Phase $^{a}$ & Countries $^{b}$ & Age range & $n^{c}$ & Main results of clinical trials & References \\
\hline $\begin{array}{l}\text { TVDV } \\
\text { U.S. Army Medical } \\
\text { Research and } \\
\text { Materiel Command }\end{array}$ & 1 & 1 & From 18 to 50 years & 40 & $\begin{array}{l}\text { POSITIVE POINTS: } \\
\text { Shown to be safe and well-tolerated. } \\
\text { Elicited predominantly anti-DENV T-cell } \\
\text { IFN- } \gamma \text { responses. } \\
\text { NEGATIVE POINTS: } \\
\text { Presents only E and PrM proteins. } \\
\text { High amounts of vaccine antigen needed. } \\
\text { Adjuvant needed. } \\
\text { Three-dose immunization regimen. } \\
\text { Differences in seroconversion rates among DENV. }\end{array}$ & (71) \\
\hline $\begin{array}{l}\text { V180 } \\
\text { Merck }\end{array}$ & 1 & 2 & From 18 to 49 years & 98 & $\begin{array}{l}\text { POSITIVE POINTS: } \\
\text { Shown to be safe. } \\
\text { Immunogenic with low amounts of vaccine antigens. } \\
\text { NEGATIVE POINTS: } \\
\text { Depends on adjuvants to be immunogenic. } \\
\text { Three-dose immunization regimen. }\end{array}$ & $(72,73)$ \\
\hline
\end{tabular}

a Phase of clinical trial.

${ }^{b}$ Countries where clinical trials have been performed or are being performed.

${ }^{c}$ Approximate number of individuals already enrolled in clinical trials.

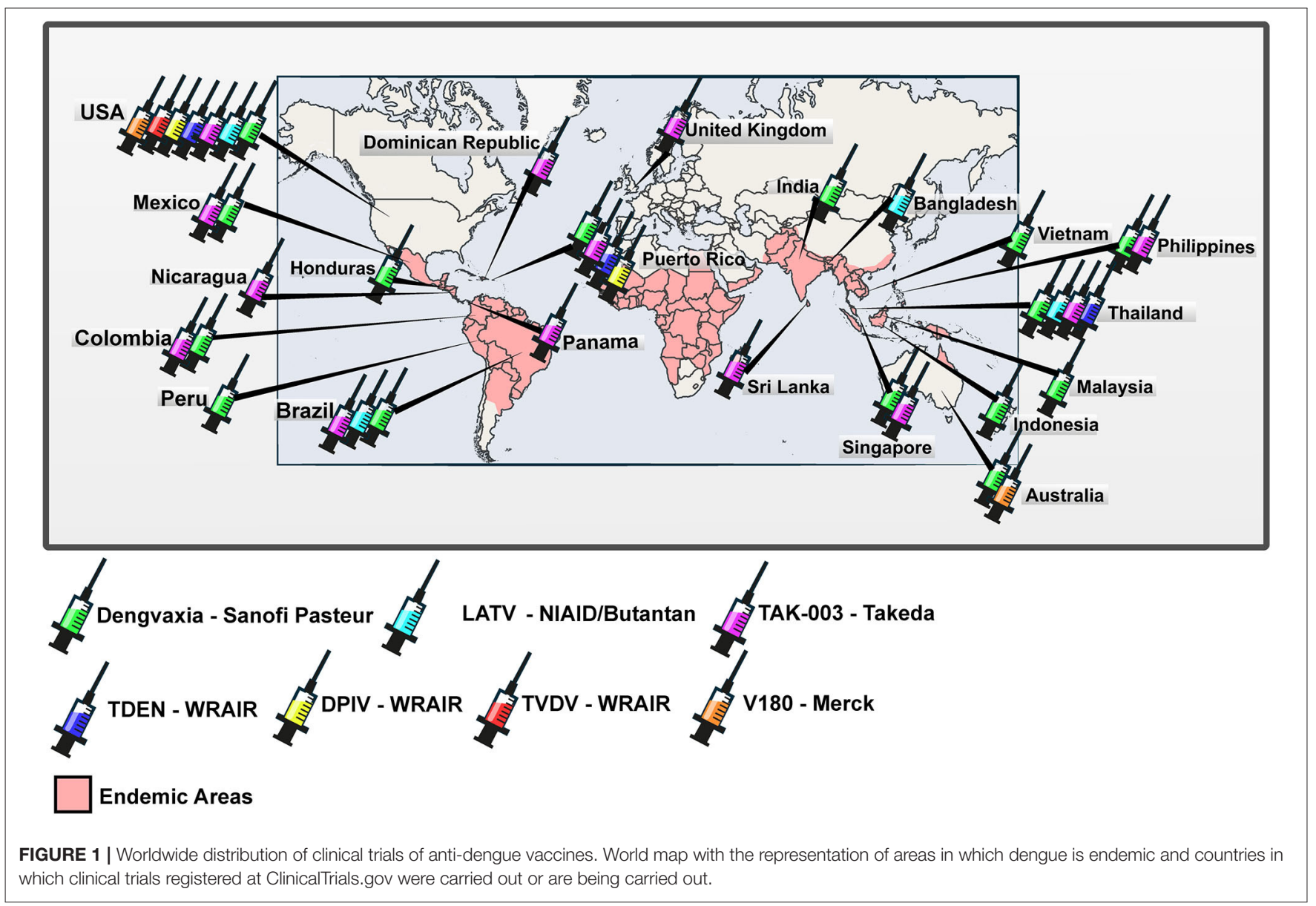

(18-20). Further phase II studies registered at ClinicalTrials.gov have been developed to assess the safety and immunogenicity of the vaccine.
As promising results were achieved in phase I and phase II clinical trials, Sanofi Pasteur carried out studies aiming to evaluate protective efficacy based on an immunization regimen 
TABLE 2 | Timeline of vaccine development.

\begin{tabular}{|c|c|c|c|c|c|c|}
\hline Current name $^{a}$ & Year & $\mathrm{Name}^{\mathrm{c}}$ & Valence & Vaccine formulation & Developer/manufacturer & Evaluation $^{d}$ \\
\hline \multirow[t]{5}{*}{ Dengvaxia $^{\circledR}$} & 1991 & $\begin{array}{l}\text { Type } 1-2 \text { and } 4 \\
\text { Chimeric Virus }\end{array}$ & Monovalent & Chimeric viruses YH/DEN1-2 and 4 & NIAID & In vitro \\
\hline & 2001 & ChimeriVax-TM & Mono/tetravalent & Chimeric viruses YF/DEN1-4 & Acambis, Inc. & In vivo (animal) \\
\hline & 2006 & $\begin{array}{l}\text { ChimeriVax }{ }^{T M_{-}} \\
\text {DEN2 }\end{array}$ & Monovalent & Chimeric virus YF/DEN2 & $\begin{array}{l}\text { Sanofi Pasteur/Acambis, } \\
\text { Inc. }\end{array}$ & In vivo (phase I trial) \\
\hline & 2011 & CYD-TDV & Tetravalent & Chimeric viruses YF/DEN1-4 & Sanofi Pasteur & In vivo (phase II-III trials) \\
\hline & 2015 & Dengvaxia $^{\circledR}$ & Tetravalent & Chimeric viruses YF/DEN1-4 & Sanofi Pasteur & Licensed \\
\hline LATV & 1996 & $\begin{array}{l}\text { rDEN1 } \Delta 30 \\
\text { rDENV2/4 } 430 \\
\text { rDENV3 } 330 / 31- \\
7164 \\
\text { rDENV4 } \Delta 30\end{array}$ & Monovalent & $\begin{array}{l}\text { Genetically attenuated virus (deletion) } \\
\text { Chimeric virus DENV2/rDEN2/4 } 330 \\
\text { Genetically attenuated virus (deletion) } \\
\text { Genetically attenuated virus (deletion) }\end{array}$ & NIAID & $\begin{array}{l}\text { In vitro and in vivo } \\
\text { (Animal and phase I trial) }\end{array}$ \\
\hline \multirow[t]{4}{*}{ TAK-003 } & 1987 & DENV2 PDK-53 & Monovalent & Virus attenuated with passages in PDK cells & University Mahidol & $\begin{array}{l}\text { In vitro and in vivo } \\
\text { (Animal and phase I trial) }\end{array}$ \\
\hline & 2003 & $\begin{array}{l}\text { DENV2 PDK-53/1 } \\
\text { DENV2 PDK-53 } \\
\text { DENV2/3 } \\
\text { DENV2/4 }\end{array}$ & Monovalent & Chimeric viruses DENV2 PDK-53/DENV1,3, or 4 & $\begin{array}{l}\text { University of Texas and } \\
\text { Inviragen, Inc. }\end{array}$ & $\begin{array}{l}\text { In vitro and in vivo } \\
\text { (Animal) }\end{array}$ \\
\hline & 2011 & DENVax1-4 & Monovalent & Chimeric viruses DENV2 PDK-53/DENV1,3, or 4 & Inviragen, Inc. & In vivo (animal) \\
\hline & 2015 & TDV & Tetravalent & Chimeric viruses DENV2 PDK-53/DENV1,3, or 4 & Takeda & In vivo (phase I-III trials) \\
\hline \multirow{3}{*}{ DPIV } & 2010 & TPIV & Tetravalent & $\begin{array}{l}\text { Purified-inactivated viruses (DENV1-4), aluminum } \\
\text { hydroxide AS01, ASO3, or ASO4 as adjuvants }\end{array}$ & NMRC', WRAIR & In vivo (animal) \\
\hline & 2015 & TDENVPIV & Tetravalent & $\begin{array}{l}\text { Purified-inactivated viruses (DENV1-4), aluminum } \\
\text { hydroxide AS01, ASO3, or ASO4 as adjuvants }\end{array}$ & $\begin{array}{l}\text { WRAIR and } \\
\text { GlaxoSmithKline }\end{array}$ & In vivo (animal) \\
\hline & 2017 & DPIV & Tetravalent & $\begin{array}{l}\text { Purified-inactivated viruses (DENV1-4), aluminum } \\
\text { hydroxide AS01, ASO3, or ASO4 as adjuvants }\end{array}$ & $\begin{array}{l}\text { WRAIR, GlaxoSmithKline } \\
\text { and Fiocruz }\end{array}$ & In vivo (phase I trial) \\
\hline \multirow[t]{5}{*}{ TVDV } & 1997 & DEN-2 & Monovalent & $\begin{array}{l}\text { DNA vaccine based on } \mathrm{pRM} \text { and } 92 \% \text { of } \mathrm{E} \text { protein } \\
\text { of DENV2 }\end{array}$ & nNMRC and Vical Inc. & In vivo (animal) \\
\hline & 2000 & DIME100 & Monovalent & $\begin{array}{l}\text { DNA vaccine based on prM and } 100 \% \text { of protein } \\
\text { E of DENV1 }\end{array}$ & WRAIR & In vivo (animal) \\
\hline & 2003 & 1040D2ME-LAMP & Monovalent & $\begin{array}{l}\text { Chimeric DNA vaccine based on prM and } \mathrm{E} \\
\text { proteins of DENV2 and the mouse } \\
\text { lysosome-associated membrane protein (LAMP). }\end{array}$ & NMRC & In vivo (animal) \\
\hline & 2006 & DEN-3 & Monovalent & $\begin{array}{l}\text { Nucleic acid vaccine DEN3: prM and protein E } \\
\text { complete }\end{array}$ & NMRC & In vivo (animal) \\
\hline & 2012 & TVDV & Tetravalent & $\begin{array}{l}\text { DNA vaccine based on prM and E protein coding } \\
\text { sequences cloned in the VR1012 plasmid } \\
\text { co-administered with VAXFECTIN }{ }^{\circledR} \text { as an } \\
\text { adjuvant. }\end{array}$ & $\begin{array}{l}\text { U.S. AMRDCk, WRAIR, } \\
\text { NMRC and Vical Inc. }\end{array}$ & $\begin{array}{l}\text { In vivo (animal and phase } \\
\text { I trial) }\end{array}$ \\
\hline
\end{tabular}


TABLE 2 | Continued

\begin{tabular}{llll}
\hline Current name ${ }^{\mathbf{a}}$ Year $^{\mathbf{b}}$ Name $^{\mathbf{c}}$ & Valence & Vaccine formulation & \multicolumn{1}{c}{ Developer/manufacturer Evaluation } \\
\hline V180 & Mono/Tetravalent & $\begin{array}{l}\text { Recombinant proteins based on prM and 80\% of Hawaii Biotech, Inc., WRAIR/n vivo (animal) } \\
\text { the E protein of DENV1-4 combined with different } \\
\text { adjuvants. }\end{array}$ \\
2018 V180 & Tetravalent & $\begin{array}{l}\text { Recombinant proteins based on prM and } 80 \% \text { of Merck \& Co., Inc. } \\
\text { the E protein of DENV1-4 combined with different } \\
\text { adjuvants. }\end{array}$
\end{tabular}

\footnotetext{
${ }^{a}$ Current name of the vaccine formulation;

${ }^{b}$ Year in which the name was used for the first time;

${ }^{c}$ Name of vaccine formulation considering the year of development step;

${ }^{d}$ Vaccine formulations were evaluated in vitro and in vivo. In vivo assays involve pre-clinical tests in animals models and/or phase I, II and III clinical trials;

e National Institute of Allergy and Infectious Diseases, National Institutes of Health;

${ }^{f}$ Department of Molecular Microbiology and Immunology, St. Louis University Medical School, St. Louis;

${ }^{g}$ Butantan Institute, São Paulo, Brazil;

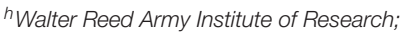

'Naval Medical Research Center;

'Oswaldo Cruz Foundation;

${ }^{k}$ U.S. Army Medical Research and Development Command.
}

composed of three doses of CYD-TDV with intervals of 6 months. In a phase IIb trial carried out with Thai children from 4 to 11 years of age, protective efficacy was shown to be $30.2 \%$ (Confidence Interval-CI 95\%: 13.4-56.6). Moreover, protective efficacy against DENV2 was shown to be 9.2\% (CI 95\%: 75-51.3) (21). However, in phase III clinical trials carried out in children from Latin America and Asia, CYD-TDV protective efficacy was shown to be of $60.8 \%$ (CI 95\%: $52.0-68.0$ ) and of $56.5 \%$ (CI 95\%: $43.8-66.4)$, respectively $(22,31)$. In such trials, protective efficacy against DENV2 was increased by 35\% (CI 95\%: 9.2-61.0). Longterm evaluations have shown that CYD's efficiency profile does not apply for all age groups.

In a study involving more than 35,000 children aging from 2 to 16 years old, the combined efficacy rate for symptomatic dengue during the first 25 months after immunization regimen was $60.3 \%$ (CI 95\%: 55.7-64.5) for all participants, $65.6 \%$ (CI 95\%: 60.7-69.9) for persons aged 9 years or older and $44.6 \%$ (CI 95\%: 31.6-55.0) for children under 9 years of age. In addition to the limited protective efficacy, vaccinated patients younger than 9 years old were at a higher risk of hospitalization due to dengue infection. Therefore, vaccination was restricted to those over 9 years of age (23). Importantly, studies have shown that the quality of the neutralizing antibodies induced by CYD-TDV varies depending on the serotype of DENV and the previous immunological status. Individuals without pre-existing DENV-specific immunity developed neutralizing antibodies to all 4 serotypes, and DENV4 was primarily neutralized by typespecific antibodies, whereas DENV1, DENV2, and DENV3 were primarily neutralized by cross-reactive antibodies (47). However, pre-existing immunity to DENV ensured the development of higher levels of neutralizing antibodies. Recent vaccine trials have demonstrated efficacy against virologically confirmed symptomatic dengue, with higher estimates of efficacy for DENV3 and DENV4, and moderate estimates of efficacy for DENV1 and DENV2 (24). In addition, it was found that hospitalization rates due to severe dengue were significantly higher in dengue naive children who received Dengvaxia (26).
Thus, the administration of this vaccine was restricted to seropositive people $(26,86)$.

Several studies were initiated aiming to evaluate the efficacy of CYD-TDV when co-administered with other vaccine antigens and adjuvants. Co-administration of YF-VAX ${ }^{\circledR}$ vaccine with CYD-TDV had no relevant impact on the immunogenicity or safety profile of the YF-VAX ${ }^{\circledR}(25)$. Other trials registered at ClinicalTrials.gov are currently underway, in order to assess the immunogenicity and safety of a CYD-TDV concomitantly administered with Adacel ${ }^{\circledR}$ (diphtheria, tetanus, and acellular pertussis adult vaccine-also called Tdap) in healthy subjects aged from 9 to 60 years in Philippines (NCT02992418), Gardasil in healthy subjects aged from 9 to 13 years in Malaysia (NCT02993757) and Cervarix ${ }^{\circledR}$ in healthy female subjects aged from 9 to 14 years in Mexico (NCT02979535).

Regarding the pattern of immune response elicited by CYDTDV, neutralizing antibodies were shown to be important. However, in a study carried out with flavivirus-naive and flavivirus-immune healthy volunteers immunized with CYDTDV, there was not triggering of detectable changes in serum pro-inflammatory cytokines. These responses were dominated by DENV4 in naive individuals, and were broadened when a booster dose was carried out 4 months after the first dose. A broader response was detected after primary tetravalent immunization in volunteers with pre-existing immunity to DENV1 or DENV2, which was elicited by a prior monovalent live-attenuated DENV immunization. In all three trials presented in the study, the profiles of cellular immune responses elicited were similar, whatever the volunteer's immune status, i.e., an absence of Th2 response, and an IFN-gamma/TNF-alpha ratio dominated by IFN-gamma, for both CD4 and CD8 T cell responses. In addition, an absence of cross-reactivity between YFV or DENV NS3-specific CD8 T cell responses was shown, which allowed the identification of 3 new CD8 epitopes in the YFV NS3 antigen (87).

In view of the promising results obtained in the various clinical studies with CYD-TDV, Mexican authorities granted 
A Dengvaxia

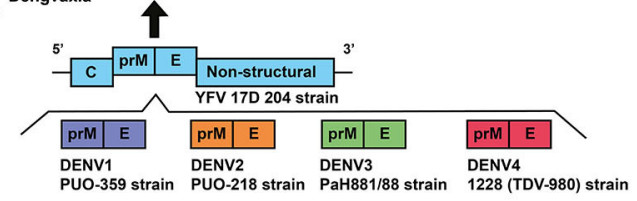

B

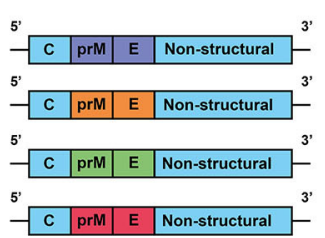

C

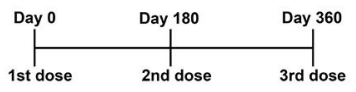

D LATV

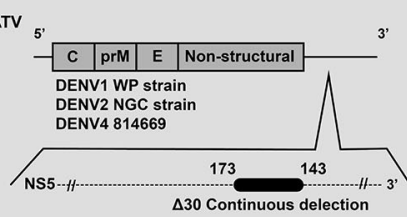

5

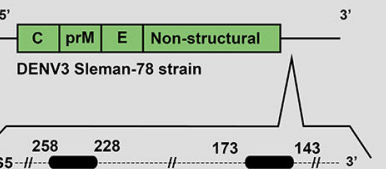

E

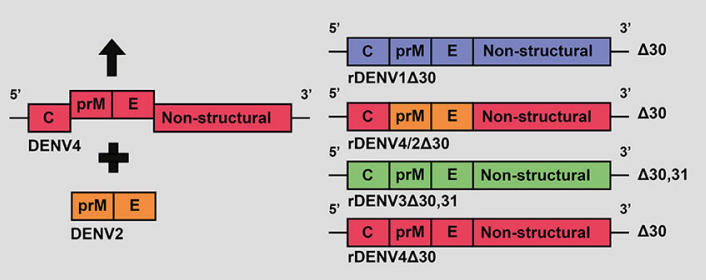

F

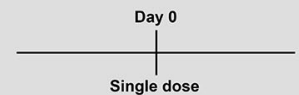

$\Delta 31$ discontinuous delection $\Delta 30$ Continuous delection

H TAK-003

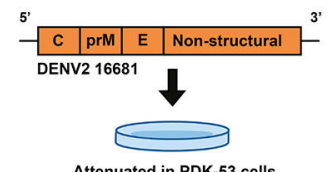

Attenuated in PDK- 53 cells
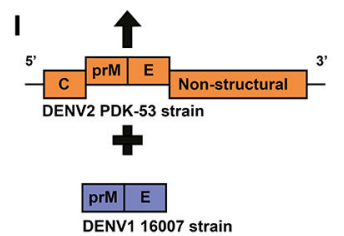

DENV1 16007 strain

\begin{tabular}{|l|l|}
\hline prM & $E$ \\
\hline
\end{tabular}

DENV3 16562 strain

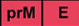

J

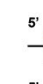

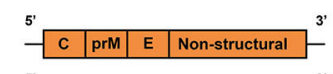

\begin{tabular}{|l|l|l|l|l|}
\hline C & prM & E & Non-structural \\
\hline
\end{tabular}

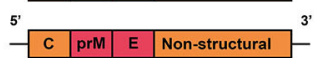

$\mathbf{K}$

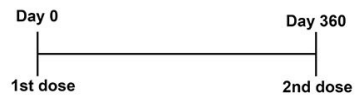

L TDEN

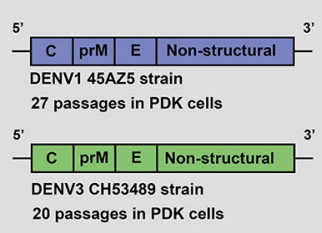

$3^{3}$

$$
5
$$$$
5
$$$$
\text { DE }
$$

DENV4 341750 strain
6 passages in PDK ce
$\mathbf{M}_{5}$

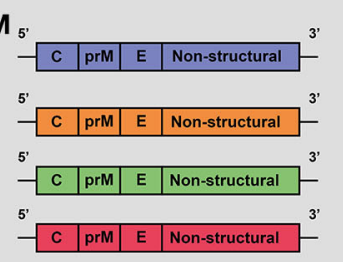

N

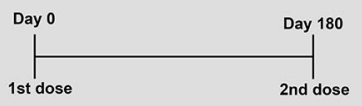

FIGURE 2 | Development of live attenuated vaccines by Sanofi, NIAID/Butantan, Takeda and U.S. Army Medical Research and Materiel Command. (A) Development of the Sanofi vaccine. The YFV 17D vaccine virus was used as a backbone for the construction of chimeric viruses, replacing its envelope protein-encoding genes with those from wild-type DENV serotypes: DENV1 (PUO-359) DENV2 (PUO-218) DENV3 (PaH881/88) DENV4 (1228). (B) Representation of genetic construction of the four DENV vaccine viruses, which compose the current Dengvaxia ${ }^{\circledR}$ tetravalent vaccine. (C) Current Sanofi vaccine immunization regimen, based on a three-dose schedule. (D) Development of NIAID/Butantan vaccine. Live attenuated vaccine viruses were generated by the introduction of continuous 30 nucleotide deletions in the $3^{\prime} U T R$ ) in DENV1 (NP), DENV2 (NGC), and DENV4 (814669). For the DENV3 Slemen-78 strain, in addition to the original 30 nucleotide deletion, an additional 31 nucleotide discontinuous deletion was carried out at the $3^{\prime} U T R$. (E) The DENV-2 component of NIAID/Butantan vaccine was generated by chimerization. prM and E genes from DENV2 (NGC) strain were introduced in replacement of those ofrDEN4 430 . (F) Representation of the four DENV1-4 vaccine constructs, which compose the current NIAID/Butantan tetravalent vaccine formulations TV003 and TV005. (G) Current vaccination regimen of NIAID/Butantan vaccine. (H) Development of Takeda's live attenuated recombinant vaccine, in which the strain 16681 DENV2 was attenuated by 53 serial passages in PDK cells. (I) Takeda DENV1, DENV3, and DENV4 vaccine antigens were developed by recombining the DENV1 (16007), DENV3 (16562), and DENV4 (1036) strains with the DENV2 PDK53 vaccine virus. (J) Representation of genetic composition of vaccine viruses contained in Takeda's vaccine. (K) Current Takeda's vaccine immunization regimen. (L) Development of TDEN vaccine formulations, in which strains 45AZ5 (DENV1), S16802 (DENV2), CH53489 (DENV3), and 341750 (DENV4) were attenuated with serial passages in PDK cells. (M) Representation of genetic composition of vaccine viruses contained in the current TDEN vaccine formulation. (N) TDEN F17 and F19 vaccine formulations were administered in two doses 180 days apart in clinical trials.

marketing authorization for Dengvaxia ${ }^{\circledR}$ on December 9, 2015 (Dengvaxia ${ }^{\circledR}$ is the current commercial name of CYD-TDV). Thus, this is the first anti-dengue vaccine to be licensed in the world. Philippines, Brazil, El Salvador, Costa Rica, Paraguay, Guatemala, Peru, Indonesia, Thailand, and Singapore also granted regulatory approval for Dengvaxia ${ }^{\circledR}$ (88). Recently, on 
December 19, 2018, the European Commission also granted marketing authorization for Dengvaxia ${ }^{\circledR}$, and although it does not contemplate the whole world, it remains the only anti-dengue licensed vaccine so far. The indication of vaccination is restricted to individuals living in endemic regions and aged between 9 to 45 years, in a three-dose vaccination regimen (Figure 2C), with the exception of Paraguay, which extended the upper age limit to 60 years (88).

\section{LATV}

The Laboratory of Infectious Diseases (LID) of the National Institute of Allergy and Infectious Diseases (NIAID) developed a live attenuated tetravalent vaccine for dengue (LATV) (89) here, vaccine's names will be used according to the history of vaccine development, as shown in Table 2. Using recombinant DNA technology, LID originally developed DENV4 attenuated virus by removing nucleotides from position $172-143$ of the $3^{\prime}$ untranslated region ( $3^{\prime}$ UTR) of the strain 814669 Dominica 1981 (89) (Figure 2D). The rDEN $4 \Delta 30$ mutant exhibited reduced infectivity and replicated less efficiently in LLC-MK2 cells when compared to the wild type virus (89). It also exhibited reduced growth in C6/36 cells, induced antibody response equivalent to a wild-type DENV1 (89), and was shown to have restricted ability to infect and disseminate in the midgut of Aedes aegypti mosquitoes (90). In clinical studies $\operatorname{rDEN} 4 \Delta 30$ was shown to be a safe and immunogenic vaccine virus $(91,92)$.

The deletion of 30 nucleotides was also carried out in a homologous region of DENV1, strain Western Pacific (WP), originating the $\operatorname{rDEN} 1 \Delta 30$ (93). Such virus was shown to be attenuated in rhesus monkeys at levels similar to $\operatorname{rDEN} 4 \Delta 30$ vaccine virus (93). All monkeys inoculated with $\mathrm{rDEN} 1 \Delta 30$ were completely protected against a challenge carried out with a wildtype DENV1. In addition, attenuation was also shown in $\mathrm{HuH}-$ 7-SCID mice (93). The replication in Toxorhynchites splendense mosquitoes was shown to be restricted (93). And in the clinical trials it was shown to be safe and immunogenic $(94,95)$.

For the development of the DENV2 vaccine virus, two methods of virus attenuation (nucleotide deletion added to chimerization) were used $(96,97)$. Chimerization was carried out by using the rDEN4 $\Delta 30$ infectious clone as a backbone. Two chimeric viruses were generated by replacing the region encoding the structural proteins in the $\operatorname{rDEN} 4 \Delta 30$ backbone with the homologous part from DENV2 strain NGC: (i) rDEN2/4 $\Delta 30$ (ME) (Figures 2D,E), with replacement of membrane $(\mathrm{M})$ and envelope (E) glycoproteins and (ii) $\mathrm{rDEN} 2 / 4 \Delta 30$ (CME), with replacement of capsid (C) protein, in addition to $\mathrm{M}$ and $\mathrm{E}$. (97). The two chimeras were shown to be highly attenuated in SCIDHuH-7 mice, mosquitoes, and rhesus monkeys (97). Due to the satisfactory results obtained in the pre-clinical tests $(94,97)$, the rDEN2/4' (ME) virus was evaluated in phase I clinical trials, in which it was shown to be safe and immunogenic (49).

Several vaccine candidates were proposed for the DENV3 (98). The first of them was developed by chimerization, with replacement of prM and $\mathrm{E}$ proteins coding regions of the rDEN4 and rDEN4 $\triangle 30$ virus with those of DENV3 (Sleman/78 strain). Two chimeric viruses were generated: $\mathrm{rDEN} 3 / 4(\mathrm{ME})$ and $\mathrm{rDEN} 3 / 4 \Delta 30$ (ME) (98). Effective attenuation was shown for the two chimeric viruses in SCIDHUH-7 mice and rhesus monkeys. Although they were shown to elicit significant titers of neutralizing antibodies, they produced detectable viremia in monkeys, and the infectivity of the viruses in the midgut of Ae. Aegypti was similar to the wild type DENV3 (98). The second approach was the deletion of 30 nucleotides in the $3^{\prime}$ UTR region of the Sleman/78 strain, originating the mutant $\mathrm{rDEN} 3 \Delta 30$ virus (98). All NHP immunized with $\mathrm{rDEN} 3 \Delta 30$ were shown to produce neutralizing antibody in titers equivalent to the wild-type DENV3, which guaranteed effective protection after challenge. However, attenuation was not seen in any tested animal model (98). The rDEN3/4 $\Delta 30$ (ME) chimeric virus was chosen for further evaluation in clinical trials, but seroconversion was observed in only $25 \%$ of volunteers (99). In view of the low attenuation of rDEN3 $\Delta 30$ in SCID-HuH-7 mice and NHP, new strategies were employed (100). Further deletions were carried out (100) in the original mutation 30 (nt173-143) of the 3'UTR region (98), and generated nine mutant viruses that were considered viable (100). The mutant virus $\mathrm{rDEN} 3 \Delta 30 / 31$, which includes the original mutation and an additional non-continuous deletion of $31 \mathrm{nt}$ (258-228) (Figure 2D), presented complete loss of replication in $\mathrm{C6} / 36$ cells, in addition to a robust replication in Vero cells. Moreover, it exhibited reduced replication in Toxorynchites mosquitoes and low infection rates in rhesus monkeys, without detectable viremia. The $\mathrm{rDEN} 3 \Delta 30 / 31$ mutant virus was also shown to elicit strong neutralizing antibody response in rhesus monkeys, capable of conferring protection against a challenge with DENV3 (100). Finally, it induced a seroconversion of $90 \%$ in volunteers in a clinical trial (50).

A phase I clinical trial evaluated the safety and immunogenicity of monovalent vaccine candidates ( $\mathrm{rDEN} 1 \Delta 30$, $\mathrm{rDEN} 2 / 4 \Delta 30$, and $\mathrm{rDEN} 3 \Delta 30 / 31-7164)$ (101). All three vaccines were well-tolerated by volunteers, with mild and short-term adverse events, with only a short-lived, low-level viremia $(<100$ PFU/mL of blood). The DEN1 $\Delta 30$ and DEN3 $\Delta 30 / 31-7164$ viruses induced $90 \%$ of seroconversion, while the $\mathrm{rDENV} 2 / 4 \Delta 30$ chimeric virus induced an immune response with low levels of specific antibodies (101).

In view of the results obtained in the pre-clinical and clinical trials with the monovalent vaccine formulations of DENV, live attenuated tetravalent vaccine (LATV) formulations were proposed to be evaluated in phase I, II, and III clinical trials in order to determine safety, reactogenicity, infectivity, immunogenicity and protective efficacy profiles. In a phase I clinical trial, four LATV formulations were evaluated: TV001 $\left(\mathrm{rDEN} 1 \Delta 30, \mathrm{rDEN} 2 / 4 \Delta 30, \mathrm{rDEN} 3-3^{\prime} \mathrm{D} 4 \Delta 30\right.$, and $\left.\mathrm{rDEN} 4 \Delta 30\right)$ TV002 (rDEN1 $\Delta 30, \quad \operatorname{rDEN} 2 / 4 \Delta 30, \quad \operatorname{rDEN} 3-3^{\prime} \mathrm{D} 4 \Delta 30$ rDEN4 $\Delta 30-200,201)$; TV003 (rDEN1 $\Delta 30, \quad$ rDEN2/4 $\Delta 30$, rDEN3 $\Delta 30 / 31$, and rDEN4 $\Delta 30$ ) (see Figure 2 F), and TV004 $(\mathrm{DEN} 1 \Delta 30, \mathrm{rDEN} 2 / 4 \Delta 30, \mathrm{rDEN} 3 \Delta 30 / 31, \mathrm{rDEN} 4 \Delta 30-200,201)$ (102). All vaccines were shown to be well-tolerated, and $93 \%$ of all local adverse events induced were of mild severity. In addition, eruption occurred in $64.2 \%$ of volunteers (102), in a similar way with regard to reactions observed with the monovalent vaccines (101). Low-level viremia occurred frequently, but with less detection for DEN2/4 $\Delta 30$ and DEN4 $\Delta 30-200,201$, and none of the participants developed fever (102). Moreover, antibody titers 
against each monovalent component were relatively balanced, inducing seroconversion rates of 50 to $100 \%$. $\mathrm{rDEN} 2 / 4 \Delta 30$ induced the lowest rates, ranging from 50 to $65 \%$. The most balanced antibody response was achieved when $\operatorname{rDEN} 3 \Delta 30 / 31$ and $\mathrm{rDEN} 4 \Delta 30$ were mixed with $\mathrm{rDEN} 1 \Delta 30$ and $\mathrm{rDEN} 2 / 4 \Delta 30$ (TV003), inducing seroconversion in $100 \%$ for DENV1 and DENV4, and 50 and $85 \%$ for DENV2 and DENV3, respectively (102). In a clinical trial with TV003, 48 healthy adults received two doses of vaccine or placebo given 12 months apart. A single dose of TV003 elicited sterilizing immunity to all 4 serotypes for at least 1 year in $80 \%$ of vaccines. Vaccine viremia was not detected in any vaccine following the second dose (51).

Phase I/II clinical trials were performed with naive flavivirus adults to demonstrate the safety and immunogenicity of two vaccine formulations (52). The TV003 vaccine formulation was previously shown to elicit better seroconversion rates $(90 \%)$ (102), and the TV005 vaccine formulation. The TV005 is similar to TV003, but with an increased amount of the DENV2 vaccine component from $10^{3}$ to $10^{4} \mathrm{PFU}$ (52). In a single dose regimen, both, TV003 and TV005 induced seroconversion to all DENV serotypes. However, the elicitation of tetravalent immune response was increased from $74 \%$ with TV003 to $90 \%$ with TV005 (52). In addition, the specific immune response to DENV2 also increased from $76 \%$ with TV003 to $97 \%$ with TV005 administration. Relevantly, both, the first dose and the second doses (given 6 months after) were well-tolerated. Importantly, a significant increase in antibody titers was not observed after the booster at 6 months (52).

Although less effective in inducing seroconversion to DENV2 if compared to TV005, the protective efficacy of TV003 was assessed in a human challenge experiments with $\operatorname{rDEN} 2 \Delta 30$ (DENV2) in DENV-naive individuals (53). Initially, $\mathrm{rDEN} 2 \Delta 30$ was developed from strain Tonga/74 of DENV2 as a vaccine candidate, with a deletion of 30 nucleotides in the 3'UTR region. However, it was shown to be infectious in Toxorynchites mosquitoes, and only slightly attenuated in rhesus monkeys (103). Moreover, it was shown to be infective and to induce signs of dengue in healthy volunteers (54). Thus, it was abandoned as a vaccine antigen, but was proposed to be used in challenge experiments (53). In this phase I clinical trial, all 24 volunteers immunized with TV003 seroconverted to DENV2, DENV3, and DENV4, while 91.7\% seroconverted to DENV1. And relevantly, all volunteers were protected after a challenge with $\mathrm{rDEN} 2 \Delta 30$ (103).

As evidenced, there have been numerous obstacles to the development of a safe and effective vaccine against dengue, and currently two single dose vaccines (see Figure 2G) are being evaluated in Phase I, II, and III clinical trials. Four phase I clinical trials involving TV003 and TV005 vaccine formulations are currently registered in ClinicalTrials.gov. In human challenge experiments, both TV003 (NCT03416036) and TV005 (NCT02317900 and NCT02873260, respectively) have been evaluated against DENV2 and DENV3. TV005 is also being evaluated regarding its safety and immunogenicity in flavivirusnaive adults (NCT02879266). Moreover, two evaluations of phase II trials (Table 1), in important dengue endemic countries, are ongoing in order to assess safety and immunogenicity of
TV003 and TV005. They are tested in adults, adolescents and children in Bangladesh (TV005 NCT02678455) and Thailand (TV003 NCT02332733). In addition, Butantan Institute (Brazil) is carrying out phase II and phase III clinical studies in Brazil with the TV003 vaccine formulation, in a partnership with NIAID. Trials are registered at ClinicalTrials.gov with codes NCT01696422 and NCT02406729. Results regarding protective efficacy are being awaited.

\section{TAK-003}

Takeda Pharmaceutical Company Limited is leading the development of a live attenuated tetravalent vaccine named as Tak-003, that is based on an attenuated virus and chimeric viruses constructed using recombinant DNA technology (104)-here, vaccine's names will be used according to the history of vaccine development, as shown in Table 2. The initial studies with the vaccine were developed in the 1980s, at the Mahidol University, in Thailand. With the aim of attenuating the viral strains DENV1 16007, DENV2 16681, and DENV4 1036, passages in primary dog kidney cells (PDK) were carried out. And the DENV3 viral strain 16562 was attenuated with passages in green monkey kidney (GMK) and fetal rhesus lung (FRhL2) cells (55, 105-109). The vaccine candidates presented no evidence of neurovirulence in mice and low viremia in monkeys. However, when tested in humans the vaccine viruses caused systemic reactions consistent with a dengue-like syndrome and the study was stopped early to avoid further risks (110). Nevertheless, the vaccine candidate DENV2 (16681) PDK 53 was shown to be promising when tested as a monovalent formulation $(106,111)$, and was used as a backbone in the constructs of the chimeric vaccine viruses of DENV1, DENV3, and DENV4 $(112,113)$ (Figures 2H,I).

The first chimera to be developed was based on the recombination of genes coding for non-structural proteins of the DENV2 PDK-53 virus with those coding for envelope proteins (prM and E) of the DENV1 16007 virus (112). The resulting DENV2/DENV1 vaccine virus preserved DENV2 PDK53 attenuation markers, such as temperature sensitivity in LLCMK2 cells, low replication in C6/36 cells and attenuation in mice. It was also shown to elicit higher titers of neutralizing antibodies against the DENV1, when compared to the DENV1 PDK-13 vaccine virus. In continuity, the constructs of vaccine candidates for DENV1, DENV3, and DENV4 were evaluated with different recombinations between wild type viruses and PDK-attenuated vaccine viruses (113). Nine chimeric viruses containing DENV1 (16007), DENV3 (16562), or DENV4 (1036) wild-type pre-membrane (prM) and envelope (E) genes within the DENV2 (16681) and the two genetic variants (PDK53$\mathrm{E}$ and PDK53-V) of the DENV2 PDK-53 vaccine virus were generated. As a result, the DENV2 PDK-53 vaccine virus was shown to be an interesting vector for the development of live, attenuated flavivirus vaccines. In addition, the DENV2 PDK53 was shown to replicate uniformly even when recombined and has the potential to induce a balanced immunity against all four serotypes of DENV (113). Thus, the University of Texas and Inviragen carried out studies to assess the safety and genetic stability of DENV2-PDK-53 vaccine virus and chimeric vaccine viruses DENV2/1, DENV2/3, and DENV2/4. 
It was shown that the vaccine virus maintained the previously defined safety characteristics, including the three main genetic attenuation loci, temperature sensitivity in mammalian cells, very low infection and dissemination in Aedes aegypti and reduction of neurovirulence in mice (114). Therefore, the DENV2-PDK53 was successfully used to produce the candidate tetravalent vaccine, which is currently being tested in clinical trials in humans $(60-62,115)$.

The DENVax vaccine, which contains the vaccine components DENV2-PDK-53 (DENVax2), DENV2/1 (DENVax1), DENV2/3 (DENVax3), and DENV2/4 (DENVax4) (Figure 2J), was subjected to pre-clinical tests carried out with mice and NHP in order to evaluate its safety, immunogenicity and protective capacity $(116,117)$. In mice, the monovalent formulations (DENVax1, DENVax2, DENVax3, and DENVax4) were shown to be safe and to elicit robust neutralizing antibody responses with protective capacity (116). In Cynomolgus monkeys, the vaccine was well-tolerated, with low levels of viremia, and induced neutralizing antibodies against the four DENV serotypes. All the immunized animals were protected from challenges carried out with DENV3 and DENV4, and a lower dose of the DENVax formulation partially protected the animals from challenges with DENV1 or DENV2 (117).

Takeda conducted a clinical trial in Colombia to evaluate the safety and immunogenicity of the tetravalent vaccine (DENVax) in flavivirus-naïve young and healthy adults. In addition, both formulations (low and high dose) were well-tolerated and induced neutralizing antibody responses to all four serotypes. However, antibody titers were lower for serotypes 3 and 4 (60). The vaccine, now renamed as TDV, was tested in flavivirusnaïve young and healthy adults with versions of the vaccine formulation differing in the amount of the DENV4 antigen. All formulations were well-tolerated and there were no reports of serious adverse effects (AE). The seroconversion rates were 84-100\% for DENV1, 96-100\% for DENV2, $83-100 \%$ for DENV3 and $33-77 \%$ for DENV4. In addition, more than $80 \%$ of participants in each group seroconverted to at least three serotypes of DENV (104). In Phase I and II clinical trials, TDV was well-tolerated in children and adults aged from 1.5 to 45 years, regardless of previous exposure to DENV. Moreover, seroconversion with production of neutralizing antibodies for all four DENV serotypes, as well as reactive T-cell mediated responses -which are required for a broad protection against dengue- were detected (115).

Phase II clinical trials were organized in dengue endemic countries (Dominican Republic, Panama and the Philippines) in order to determine the safety and immunogenicity of TDV. Healthy participants aged from 2 to 17 years, received one or two doses of the vaccine (Figure $2 \mathbf{K}$ ), with intervals of 3 months $(61,62)$. The reactogenicity profiles were acceptable, with neutralizing antibodies being elicited against all DENV serotypes, regardless of previous exposure to DENV. In addition, the trials demonstrated that a second dose of TDV induces increased immunogenicity against DENV3 and DENV4 in flavivirus-naïve persons, suggesting that a two-dose regimen of TDV induces a more robust humoral immune response. Recently, Takeda presented primary efficacy data from part 1 of an ongoing phase 3 randomized trial of a tetravalent dengue vaccine candidate (named as TAK-003) in regions of Asia and Latin America in which the disease is endemic. The immunization regimen was composed of two doses of TAK-003 in children and adolescents 4-16 years of age (see Figure $2 \mathrm{~K}$ ). As a result, they showed an overall vaccine efficacy in the safety population of $80.9 \%$ (118). In addition, a $95.4 \%$ efficacy against dengue leading to hospitalization was reported (118).

\section{TDEN F17/F19}

The Walter Reed Army Institute of Research (WRAIR) developed a live-attenuated, tetravalent dengue (TDEN) vaccine in collaboration with GlaxoSmithKline (GSK)-here, vaccine's names will be used according to the history of vaccine development, as shown in Table 2. The vaccine formulation consists of viruses obtained from natural infections that were isolated in C6/36 cells and then attenuated with serial passages in PDK cells. The 341750 strain of DENV4 was the first TDEN vaccine virus to be attenuated with 20 passages, in the early beginning of the 1990's. Thereafter, the following viral strains were also attenuated in PDK cells: 45AZ5 strain of DENV1, with 20 passages; S16803 strain of DENV2, with 50 passages; and CH53489 strain of DENV3, with 20 passages (see Figures 2L,M). Vaccine bulks were prepared with propagation of viruses in FrhL cells. All steps of development and production of vaccine formulation were evaluated regarding presence of contaminating agents. Pre-clinical studies carried out in Rhesus monkeys with both, monovalent and tetravalent versions of TDEN, previously named as DENV vaccine, revealed they are safe (119).

Aiming to identify the best dosage of vaccine components, 16 tetravalent formulations differing in their vaccine virus content were subjected to a phase I clinical trial with flavivirus-naïve adults. As a result, the formulations 13 and 14 were selected for further evaluations (120). A new formulation (F17pre) was developed aiming to optimize the neutralizing antibody response. It was prepared with 27 and six passages of DENV1 and DENV4 in PDK cells, respectively. F17pre, F13 and F14 were then subjected to a phase II clinical trial with two doses given with a 6month interval to flavivirus-naïve adults. Few grade $3 \mathrm{AE}$ were reported. In addition, the seroconversions to DENV serotypes elicited after a second dose were less variable in F17pre group: $69,100,81$, and $94 \%$ to $1,2,3$, and 4 serotypes, respectively (121). The F17pre vaccine was selected to be the precursor of two formulations: F17 and F19, both re-derived by propagation in FrhL cells. In a phase II clinical trial, F17 and F19 formulations elicited 37.9 and $40 \%$ of tetravalent seroconversion, respectively (65). Moreover, F19 was shown to be the safest formulation: $15.4 \%$ of the subjects reported injection site pain, whereas the rate for F17 was near 35\%, and $100 \%$ of flavivirus-primed subjects seroconverted to all four DENV antibodies when immunized with F19, against $97.1 \%$ for F17 (122).

In a randomized phase II clinical trial conducted in Puerto Rico, the seroconversion rates for all DENV serotypes revealed a similar immunogenic profile for both formulations. The F17 elicited higher titers of neutralizing antibodies after a second dose. Moreover, F17 elicited 100\% seroconversion to all serotypes in primed subjects, while F19 induced $98.4 \%$ of seroconversion for DENV2, DENV3, and DENV4. Among the non-primed volunteers, the values were variable for both formulations. The 
lowest rate of seroconversion after immunization with F17 was observed for DENV3: 92.7\%. However, F19 was shown to induce seroconversion in $78 \%$ of non-primed volunteers (66). Despite the better immunogenic profile of F17 with regard to F19, both vaccines were shown to be safe and immunogenic in primed and non-primed volunteers. In order to assess the safety and immunogenicity profiles of the TDEN F17 vaccine, a pilot study was conducted in 6-7 years old Thai children who were shown to be naïve for DENV1-4 and Japanese encephalitis virus (JEV) (67). Results of the study showed that the vaccine is safe and immunogenic and contributed to the advance to a phase I/II trial in infants aged 12-15 months. Volunteers tolerated the vaccine well without any AE, and after the second dose, $85.7 \%$ of them developed an immune response to at least three DENV serotypes. In addition, $53.6 \%$ of immunized volunteers seroconverted to the four serotypes of DENV (68). To date, the vaccine has been shown to be safe and immunogenic in volunteers ranging from 12 months to 50 years of age, when administered in a two-dose regimen (Figure $\mathbf{2 N}$ ). However, a study enrolled in the ClinicalTrials.gov (NCT01843621) aims to understand more about TDEN F17, through a 5-year follow-up of the volunteers who received the two doses of the vaccine in the previously cited trial (67). It will also assess the safety and immunogenicity of a third dose administered 1 year after the second dose, and its results may contribute to elucidate the schedule of administration for this candidate vaccine.

\section{DPIV}

The tetravalent dengue purified inactivated vaccine (DPIV) was developed by the Walter Reed Army Institute of Research (WRAIR) and is manufactured by the WRAIR Pilot Bioproduction Facility and adjuvanted by GlaxoSmithKline (GSK) adjuvant systems-here, vaccine's names will be used according to the history of vaccine development, as shown in Table 2. The vaccine development started in 1995, when a DENV2 (S16803 strain) was isolated from a patient in C6/36 cells and then propagated in Vero cells by three passages. A master seed was prepared at passage two and a production seed at passage three. Difficulties in virus propagation, as well as the apparent antigenic instability after formalin inactivation, led the inactivated vaccines to have their viability questioned. Nevertheless, the purified inactivated virus (PIV) was shown to be safe when administered to mice, which developed significant neutralizing antibodies titers and $100 \%$ of seroconversion after the second dose (123). Further, the PIV was shown to be safe and immunogenic when administered to Rhesus monkeys. In addition, an immunization regimen based on two doses administered 3 months apart was shown to be safe, without exhibition of redness or swelling at the vaccination sites. Moreover, neutralizing antibody titers were reported in 37 of 39 vaccinated animals (124).

Years later, a tetravalent formulation based on inactivated viruses named as TPIV (tetravalent purified-inactivated virus), was developed and subjected to immunization assays in Rhesus monkeys using three other virus strains derived from human isolates: West pac 74 for DENV1, CH53489 for DENV-3, and TVP360 for DENV-4; in addition to the previously mentioned strain of DENV2. Viruses propagated in Vero cells were subjected to sucrose gradient ultracentrifugation purification approach, followed by formalin inactivation and addition of $0.01 \%(\mathrm{v} / \mathrm{v})$ alum (aluminum hydroxide) (125) as an adjuvant (Figures 3A,B). The immunization regimen was composed of a first dose of TPIV followed by a booster dose of a tetravalent live attenuated vaccine (TLAV). Such a vaccine regimen elicited virus neutralizing antibodies. The TPIV/TLAV combination afforded complete protection against DENV 3 challenge at month 8 . In a second experiment, priming with TPIV elicited neutralizing antibodies against all four serotypes of DENV. After challenge with each one of the four DENV serotypes, vaccinated animals exhibited no viremia but showed anamnestic antibody responses to the challenge viruses.

Renamed as TDEN PIV, the vaccine formulation based on inactivated viruses was subjected to an evaluation regarding adjuvants options in Rhesus monkeys. As a result, most of adjuvants tested helped to prevent viremia after challenge, with the DENV1 and DENV2 administered at 40 and 32 weeks postdose 2, respectively (126). Afterwards, a monovalent vaccine formulation based on the DENV1 West pac 74 strain was prepared by nine passages in Rhesus monkey lung (FrhL) diploid cell cultures followed by three passages in Vero cells. Such a vaccine was subjected to a phase I clinical trial in a nonendemic area of the United States, and was shown to be safe and moderately immunogenic. Volunteers were immunized in a twodose regimen; 28 days apart. A low number of subjects reported mild pain or tenderness after the first injection. Seroconversion reached $100 \%$ in volunteers 2 weeks after the second dose (127). Such results guided vaccine developers to replace alum with $\mathrm{AS}_{\mathrm{E}}$ (3-O-desacylcinomonophosphoryl lipid A) and $\mathrm{ASO} 3_{\mathrm{B}}$ (Oil-in-water emulsion) adjuvant systems, aiming to overcome problems with immunogenicity caused by inactivation. Their combination has been demonstrated to induce early mobilization of neutrophils and monocytes $(128,129)$.

More recently, the tetravalent vaccine formulation, named as DPIV and adjuvanted by AS01E/AS03B, was evaluated in a phase I clinical trial with 100 healthy adults, also in the United States. Volunteers were immunized in a regimen of two doses, with an interval of 28 days (Figure 3C). In agreement with the previous trial, pain, redness and swelling were frequently reported. Neutralizing antibody responses against all four DENV serotypes were balanced in the dengue-naive adults, but decreased over time (69). Moreover, DPIV was shown to induce high titers of neutralizing antibodies in a phase I clinical trial carried out in Puerto Rico. The best results were achieved when $\mathrm{ASO}_{\mathrm{B}}$ was used as an adjuvant (70).

The humoral responses observed with administration of vaccine formulations based on inactivated viruses were robust, though it is still unknown whether DPIV is able to provide long lasting immunity. Despite presenting a balanced antibody responses against the four serotypes, the inactivated nature of vaccine antigens may still generate obstacles regarding immune response to non-structural proteins. As described above, only envelope and capsid proteins were targeted by the immune system after immunization regimens with DPIV. The vaccine was unable to control DENV infection in challenge assays carried 
A DPIV

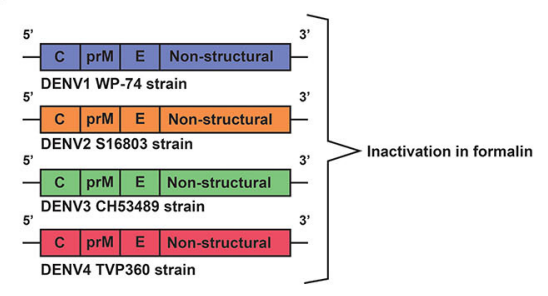

B

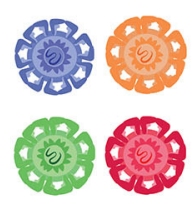

C

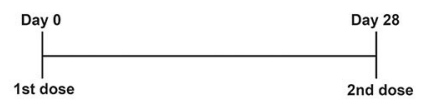

\section{TVDV}

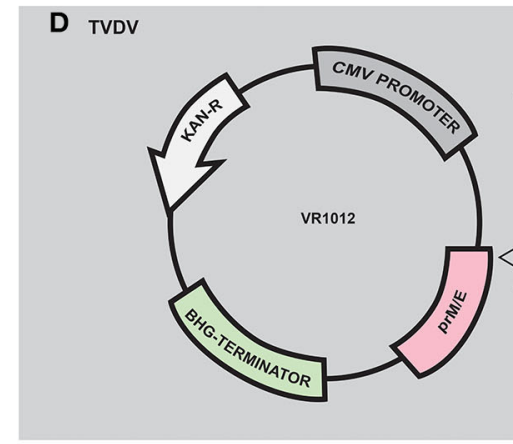

G V180

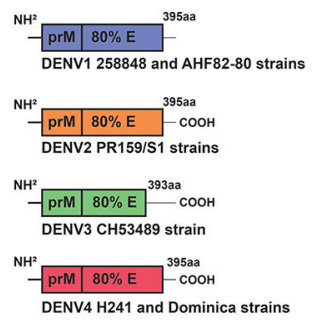

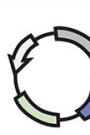

8

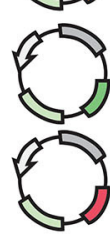

$\mathbf{H}$

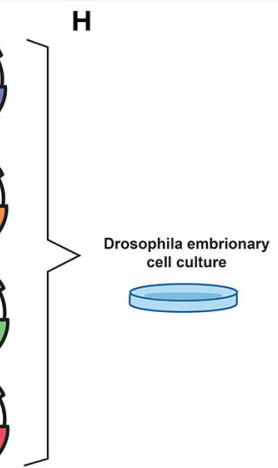

(2)

E
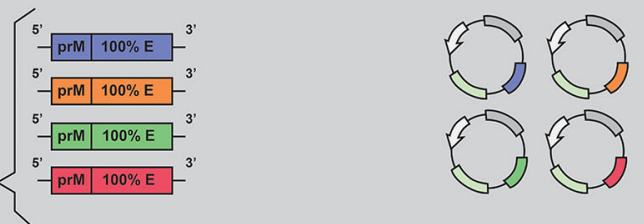

F

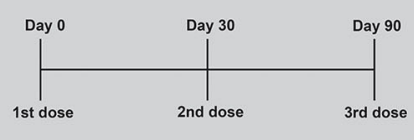

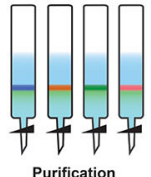

I
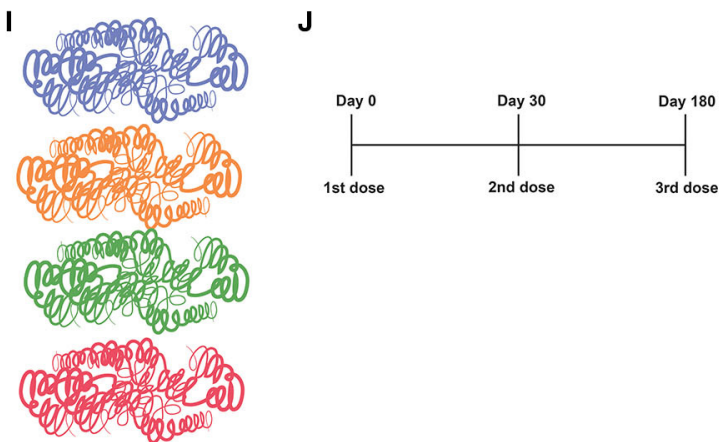

1st dos

FIGURE 3 | Development of inactivated (DPIV) and DNA (TVDV) vaccines by the U.S. Army Medical Research and Materiel Command; and the development of the V180 subunit vaccine by Merck. (A) DPIV is composed of formalin-inactivated viral particles of DENV1 WP-74, DENV2 S16803, DENV3 CH53489, and DENV4 TVP360 strains. (B) Representation of the four vaccine constructs which compose the current DPIV vaccine formulation. (C) Representation of DPIV immunization regimen, which consists of two doses 28 days apart. (D) Development of the tetravalent DNA vaccine (TVDV). Genetic constructs encoding prM and E proteins of DENV1 (west Pac74), DENV2 (New Guine C strain), DENV3 (Asian strain) and DENV4 were cloned into Plasmid VR1012. (E) Representation of the genetic constructs which are the vaccine antigens of the current TVDV vaccine. (F) The TVDV immunization regimen consists of three doses administered on days 0, 30, and 60. (G) Development of a tetravalent vaccine based on prM and 80\% (ectodomain) of the E protein (V180). Coding regions of prM and E protein ectodomain of DENV1 (258848 and AHF82-80 strains), DENV2 (PR159/51), DENV33 (CHS3489), and DENV4 (H242 Dominica) were cloned into expression plasmids. (H) Drosophila Schneider-2 (S2) cells were used for expression of prM/E. Recombinant vaccine antigens were purified by immunoaffinity chromatography. (I) Representation of proteins that compose the current $\mathrm{V} 180$ vaccine formulation. $\mathbf{( J )}$ The immunization regimen used in the $\mathrm{V} 180$ clinical trial consisted of three doses administered on days 0,30 , and 180 .

out with immunized rhesus macaques. Importantly, increased levels of viremia, aspartate transaminase, IL-10, IL-18 and IFN$\gamma$, and reduced levels of IL-12 were detected in immunized NHP, indicating that vaccination may have triggered antibodydependent enhancement of DENV infection (130).

\section{TVDV}

A tetravalent DNA vaccine against dengue (TVDV) was developed by the U.S. Army Medical Research and Materiel Command-here, vaccine's names will be used according to the history of vaccine development, as shown in Table 2. It is based on the genes that code for the entire pre-membrane (prM) and envelope (E) proteins and is currently being tested in a Phase I clinical trial $(71,131,132)$.

The monovalent version of the DNA vaccine against DENV1, initially named as DIME100, is derived from West Pacific strain 74 consisting of prM and E genes cloned into the plasmid VR1012 (133) (Figures 3D,E). Such vaccine formulation was shown to be immunogenic and to protect Rhesus monkeys under challenge assays. It was also shown to be immunogenic in phase I clinical trials (131).

It was first shown to be immunogenic and to protect mice under challenge assays with DENV2 when co-administered with CpG motifs $(134,135)$ (Figures 3D,E). Then, the original 
construct was modified by replacing the DENV2 transmembrane and cytoplasmic sequences with those of the mouse lysosomeassociated membrane protein. At that time, the vaccine was renamed as 1040D2ME-LAMP (136). Such modification strategy targets MHC class II compartment and elicits long-lasting neutralizing antibodies.

The DENV3 antigen was derived from an Asian viral strain and is composed of prM and E, which were cloned in VR1012 plasmid (Figures 3D,E). Preclinical tests carried out with Aotusnancymae showed that the DENV3 monoclonal vaccine elicits neutralizing antibody and moderate levels of specific IgG. In addition, it was also shown to confer partial protection in challenge assays (137).

The genetic construction of DENV4 is similar to that of DENV3 (Figures 3D,E). However, there is a lack of reports showing results of preclinical tests in its monovalent form. Nevertheless, a tetravalent vaccine (TVDV) formulation initially based on shuffled constructs was developed. Three formulations were initially proposed: $\mathrm{sA}$ and $\mathrm{sC}$ (based on prM and $\mathrm{E}$ ) and $\mathrm{sB}$ (encoding envelope protein ectodomain only). Such constructs were administered to Rhesus monkey and only those immunized with sA and sC produced antibodies to the four serotypes (138).

In a subsequent study, Vaxfectin ${ }^{\circledR}$ was used as an adjuvant aiming to improve immunogenicity of a tetravalent vaccine formulation based on non-chimeric genetic constructs. These constructs were prepared by combining equal amounts of monovalent plasmid DNA vaccines that encode the premembrane (prM) and envelope (E) genes of DENV1-4 cloned into the VR1012 plasmid. In an immunization regimen composed by three doses (Figure 3F), the use of Vaxfectin ${ }^{\circledR}$ resulted in a significant increase in anti-DENV neutralizing antibody responses against DENV1, DENV2, and DENV3. In addition, co-administration of TVDV adjuvanted with Vaxfectin ${ }^{\circledR}$ diminished the time of viremia in challenged animals (131). The tetravalent formulation containing Vaxfectin ${ }^{\circledR}$ was also tested in New Zealand white rabbits for evaluation of safety and immunogenicity and animals receiving two doses of the vaccine formulation were shown to seroconvert to the four serotypes of DENV (132). Finally, in a phase I clinical trial (NCT01502358) carried out with 40 flavivirus-naïve volunteers, TVDV was shown to be safe and well-tolerated and elicited dose-dependent anti-DENV T-cell IFN- $\gamma$ responses (71).

\section{V180}

A vaccine formulation based on recombinant forms of the DENV envelope glycoprotein was initially developed by Hawaii biotech and named as DEN-80 due to its composition, based on the ectodomains of the E protein of each DENV serotype, which correspond to $80 \%$ of the whole protein- here, vaccine's names will be used according to the history of vaccine development, as shown in Table 2. Currently, the product is being developed by Merck and the vaccine formulation is adjuvanted by ISCOMATRIX $^{\mathrm{TM}}$ (139).

Genetic constructs of the tetravalent vaccine formulation V180 were prepared by RT-PCR- based amplification of viral sequences coding for prM and truncated $\mathrm{E}$ proteins, with subsequent digestion and cloning into pMtt $\Delta$ Xho vector (139) (derived from pMttPA and pMttbns plasmids). The following viral sources were used for RT-PCR: DENV1 strain 258848 and DENV1 Thailand AHF82-80 (GenBank accession number D00502); DENV2 strain PR159/S1 (140, 141); DENV3 strains CH53489 and D3H87 (142) and DENV4 strains H241 and Dominica (143) (Figure 3G). Drosophila Schneider-2 (S2) cells were used for the expression of the $\mathrm{prM} / \mathrm{E}$ sequences with secretion of the vaccine antigen for each serotype. Finally, the recombinant vaccine antigens were purified by immunoaffinity chromatography (139) (Figures 3H,I).

In preclinical tests carried out with mice and non-human primates (NHP), the monovalent vaccine formulation composed by ISCOMATRIX adjuvant and DEN2-80E was shown to elicit neutralizing antibodies and to confer protective immunity under lethal challenge assays using the virulent DENV2 strains New Guinea C and S16803. The vaccine formulation was shown to elicit a Th1 profile of cellular immune response with detection of memory cells 6 months after the last immunization (139).

Such positive results regarding immunogenicity were attributed to the high quality of the recombinant proteins, in addition to the use of ISCOMATRIX ${ }^{\mathrm{TM}}$ as an adjuvant, which contributed to the achievement of protective immunity with low amounts of vaccine antigen per dose $(139,144)$. In addition, the tetravalent version of the vaccine formulation, named as V180, was shown to induce higher levels of neutralizing antibodies with an immunization regimen based on doses given at days 0,30 , and 180 (72) (see Figure 3J). Moreover, clinical trials NCT00936429, NCT01477580, showed that V180 induced moderate levels of neutralizing antibodies in human volunteers, with $85.7 \%$ seroconversion. It is important to stress that immunogenicity of the vaccine formulation depends on the adjuvant. Conclusion of clinical validation of the vaccine formulation is required in order to define if it is safe and effective.

\section{DISCUSSION}

The advance in vaccine development against dengue is welcome. There is to date one vaccine formulation licensed for use in countries in which the disease is endemic and two other vaccine formulations being tested at phase III clinical trials. However, neutralizing antibodies have been assumed as the main correlate of protection. This is questionable and ignores the key role of T-cell mediated immunity in controlling DENV infection. Dengvaxia ${ }^{\circledR}$ is the most tested anti-dengue vaccine, as can be seen in Figure 1. However, as can be seen in Table 1, it is clear that the lack of DENV non-structural proteins led to a low protective efficacy, especially for children. In addition, children had their risk of hospitalization increased by the use of the vaccine. Moreover, the immunization schedule is composed of three doses and the vaccine cannot be administered to Flavivírus-naïve persons. It seems to be a good model to understand that envelope proteins alone are not able to induce protective immunity. This statement is reinforced by the low or lack of protective capacity of vaccine formulations which induce solely humoral immune response against structural proteins. T cell-based immunity is essential in controlling DENV 
infection and most of the key targets are located at nonstructural proteins $(145,146)$. Fortunately, vaccine formulations which contain both, structural and non-structural proteins are under clinical trials and one of them (TAK-003) showed a relevant protective efficacy of $80.9 \%$ (118). Hopefully, other anti-dengue vaccine formulations will show equivalent or higher protective capacity and will be licensed for use in the near future.

\section{AUTHOR CONTRIBUTIONS}

JP-M carried out bibliographic review, participated in the preparation of figures and tables, and wrote the manuscript. RS carried out the bibliographic review, participated in preparation of figures, and wrote the paper. IS carried out bibliographic

\section{REFERENCES}

1. Mendoza-montero AJ, Clinical S, Diseases I, Sep N, Mendoza-montero J, Rosa-fraile M De, et al. Infections due to sandfly fever virus serotype toscana in spain. Clin Infect Dis. (1998) 27:434-6. doi: 10.1086/514684

2. Lindenbach BD, Thiel H-J, Rice CM. Fields Virology. In Knipe DM, Howley PM, editors. Flaviviridae: The Viruses and Their Replication. Philadelphia, PA: Lippincott-Raven (2007). p. 1101-33.

3. Guzman MG, Harris E. Dengue. Lancet. (2015) 385:453-65. doi: 10.1016/S0140-6736(14)60572-9

4. Bhatt S, Gething PW, Brady OJ, Messina JP, Farlow AW, Moyes CL, et al. The global distribution and burden of dengue. Nature. (2013) 496:504-7. doi: $10.1038 /$ nature 12060

5. Gubler DJ. The changing epidemiology of yellow fever and dengue, 1900 to 2003: full circle? Comp Immunol Microbiol Infect Dis. (2004) 27:319-30. doi: 10.1016/j.cimid.2004.03.013

6. Crill WD, Roehrig JT. Monoclonal antibodies that bind to domain III of dengue virus $\mathrm{E}$ glycoprotein are the most efficient blockers of virus adsorption to vero cells. J Virol. (2001) 75:7769-73. doi: 10.1128/JVI.75.16.7769-7773.2001

7. Lok S-M, Kostyuchenko V, Nybakken GE, Holdaway HA, Battisti AJ, Sukupolvi-Petty S, et al. Binding of a neutralizing antibody to dengue virus alters the arrangement of surface glycoproteins. Nat Struct Mol Biol. (2008) 15:312-7. doi: 10.1038/nsmb.1382

8. Beltramello M, Williams KL, Simmons CP, Macagno A, Simonelli L, Quyen NTH, et al. The human immune response to dengue virus is dominated by highly cross-reactive antibodies endowed with neutralizing and enhancing activity. Cell Host Microbe. (2010) 8:271-83. doi: 10.1016/j.chom.2010. 08.007

9. Lai C-Y, Tsai W-Y, Lin S-R, Kao C-L, Hu H-P, King C-C, et al. Antibodies to envelope glycoprotein of dengue virus during the natural course of infection are predominantly cross-reactive and recognize epitopes containing highly conserved residues at the fusion loop of domain II. J Virol. (2008) 82:663143. doi: 10.1128/JVI.00316-08

10. Oliphant T, Nybakken GE, Engle M, Xu Q, Nelson CA, Sukupolvi-petty $\mathrm{S}$, et al. Antibody recognition and neutralization determinants on domains I and II of west nile virus envelope protein. J Virol. (2006) 80:12149-59. doi: 10.1128/JVI.01732-06

11. Halstead SB. In vivo enhancement of dengue virus infection in rhesus monkeys by passively transferred antibody. J Infect Dis. (1979) 140:527-33. doi: 10.1093/infdis/140.4.527

12. Halstead SB. Personal view achieving safe, effective, and durable zika virus vaccines : lessons from dengue. Lancet Infect Dis. (2017) 17:E378-82. doi: 10.1016/S1473-3099(17)30362-6

13. Guy B, Coudeville L, Noriega F, Savarino S, Ochiai RL, Verdier F, et al. A recombinant live attenuated tetravalent vaccine for the prevention of dengue. Expert Rev Vaccines. (2017) 16:1-13. doi: 10.1080/14760584.2017.1335201 review, participated in preparation of figures, and wrote the paper. PS carried out bibliographic review and participated in preparation of figures. EM carried out bibliographic review and wrote the paper. WL carried out bibliographic review and wrote the paper. JA carried out bibliographic review and wrote the paper. All authors contributed to the article and approved the submitted version.

\section{ACKNOWLEDGMENTS}

We are thankful to Conselho Nacional de Desenvolvimento Científico e Tecnológico $(\mathrm{CNPq})$ for providing undergraduate research fellowship to IS. We are also grateful to Coordenação de Aperfeiçoamento de Pessoal de Nível Superior (CAPES) for providing graduate fellowship to JP-M.

14. Dayan GH, Garbes P, Noriega F, De Sadovsky ADI, Rodrigues PM, Giuberti $\mathrm{C}$, et al. Immunogenicity and safety of a recombinant tetravalent dengue vaccine in children and adolescents ages 9-16 years in Brazil. Am J Trop Med Hyg. (2013) 89:1058-65. doi: 10.4269/ajtmh.13-0304

15. Villar LÁ, Rivera-medina DM, Arredondo-garcía JL, Boaz M. Safety and immunogenicity of a recombinant tetravalent dengue vaccine in 9-16 year olds: a randomized, controlled, phase II trial in latin America. Pediatr Infect Dis J. (2013) 32:1102-9. doi: 10.1097/INF.0b013e31829b8022

16. Qiao M, Shaw D, Forrat R, Wartel-Tram A, Lang J. Priming effect of dengue and yellow fever vaccination on the immunogenicity, infectivity, and safety of a tetravalent dengue vaccine in humans. Am J Trop Med Hyg. (2011) 85:724-31. doi: 10.4269/ajtmh.2011.10-0436

17. Lanata CF, Andrade T, Gil AI, Terrones C, Valladolid O, Zambrano $\mathrm{B}$, et al. Immunogenicity and safety of tetravalent dengue vaccine in 2 - 11 year-olds previously vaccinated against yellow fever : randomized, controlled, phase II study in Piura, Peru. Vaccine. (2012) 30:5935-41. doi: 10.1016/j.vaccine.2012.07.043

18. Leo YS, Wilder-smith A, Archuleta S, Shek LP, Chong CY, Leong HN, et al. Immunogenicity and safety of recombinant tetravalent dengue vaccine (CYD-TDV) in individuals aged 2 - 45 years Phase II randomized controlled trial in Singapore. Hum Vaccin Immunother. (2012) 8:1259-71. doi: $10.4161 /$ hv. 21224

19. Tran NH, Luong CQ, Vu TQH, Forrat R, Lang J, Vu QD, et al. Safety and immunogenicity of recombinant, live attenuated tetravalent dengue vaccine (CYD- TDV) in healthy vietnamese adults and children. J Vaccine Vaccin. (2012) 3:7. doi: 10.4172/2157-7560.1000162

20. Kirstein J, Douglas W, Thakur M, Boaz M, Papa T, Skipetrova A, et al. Immunogenicity of the CYD tetravalent dengue vaccine using an accelerated schedule: randomised phase II study in US adults. BMC Infect Dis. (2018) 18:1-11. doi: 10.1186/s12879-018-3389-x

21. Sabchareon A, Wallace D, Sirivichayakul C, Limkittikul K, Chanthavanich $\mathrm{P}$, Suvannadabba $\mathrm{S}$, et al. Protective efficacy of the recombinant, liveattenuated, CYD tetravalent dengue vaccine in Thai schoolchildren: a randomised, controlled phase $2 \mathrm{~b}$ trial. Lancet. (2012) 380:1559-67. doi: 10.1016/S0140-6736(12)61428-7

22. Capeding MR, Tran NH, Hadinegoro SRS, Ismail HIHM, Chotpitayasunondh $\mathrm{T}$, Chua $\mathrm{MN}$, et al. Clinical efficacy and safety of a novel tetravalent dengue vaccine in healthy children in Asia: a phase 3, randomised, observer-masked, placebo-controlled trial. Lancet. (2014) 384:1358-65. doi: 10.1016/S0140-6736(14)61060-6

23. Hadinegoro SR, Arredondo-García JL, Capeding MRC, Deseda T, Chotpitayasunondh R, Dietze $\mathrm{HI}$, et al. Efficacy and long-term safety of a dengue vaccine in regions of endemic disease. N Engl J Med. (2015) 373:1195-206. doi: 10.1056/NEJMoa1506223

24. Byers AM, Broder R, Haupfear K, Timiryasova TM, Hu BT, Boaz M, et al. Influence of Fc $\gamma$ riia-expressing cells on the assessment of neutralizing and enhancing serum antibodies elicited by a live-attenuated tetravalent 
dengue vaccine. Open Forum Infect Dis. (2015) 2:ofv172. doi: 10.1093/ofid/ ofv172

25. Lopez P, Lanata CF, Zambrano B, Cortes M, Andrade T, Amemiya I, et al. Immunogenicity and safety of yellow fever vaccine (Stamaril) when administered concomitantly with a tetravalent dengue vaccine candidate in healthy toddlers at 12-13 months of age in Colombia and Peru a randomized trial. Pediatr Infect Dis J. (2016) 35:1140-7. doi: 10.1097/INF.0000000000001250

26. Sridhar S, Luedtke A, Langevin E, Zhu M, Bonaparte M, Machabert T, et al. Effect of dengue serostatus on dengue vaccine safety and efficacy. $N$ Engl J Med. (2018) 379:327-40. doi: 10.1056/NEJMoa1800820

27. Harenberg A, Begue S, Mamessier A, Gimenez-Fourage S, Seah CC, Liang AW, et al. Persistence of Th1/Tc1 responses one year after tetravalent dengue vaccination in adults and adolescents in Singapore. Hum Vaccines Immunother. (2013) 9:2317-25. doi: 10.4161/hv.25562

28. Plennevaux E, Sabchareon A, Limkittikul K, Chanthavanich P, Sirivichayakul C, Moureau A, et al. Detection of dengue cases by serological testing in a dengue vaccine efficacy trial: utility for efficacy evaluation and impact of future vaccine introduction. Vaccine. (2016) 34:2707-12. doi: 10.1016/j.vaccine.2016.04.028

29. Dubey AP, Agarkhedkar S, Chhatwal J, Narayan A, Ganguly S, Wartel $\mathrm{TA}$, et al. Immunogenicity and safety of a tetravalent dengue vaccine in healthy adults in India: a randomized, observer-blind, placebocontrolled phase II trial. Hum Vaccines Immunother. (2016) 12:512-8. doi: 10.1080/21645515.2015.1076598

30. Dayan GH, Galán-Herrera JF, Forrat R, Zambrano B, Bouckenooghe A, Harenberg A, et al. Assessment of bivalent and tetravalent dengue vaccine formulations in flavivirus-naive adults in Mexico. Hum Vaccines Immunother. (2014) 10:2853-63. doi: 10.4161/21645515.2014.972131

31. Villar L, Dayan GH, Arredondo-García JL, Rivera DM, Cunha R, Deseda C, et al. Efficacy of a tetravalent dengue vaccine in children in latin America. $N$ Engl J Med. (2015) 372:113-23. doi: 10.1056/NEJMoa1411037

32. Arredondo-García JL, Hadinegoro SR, Chansinghakul D, Perroud AP, Sanchez L, Cortés Supelano M, et al. Four-year safety follow-up of the tetravalent dengue vaccine efficacy randomized controlled trials in Asia and Latin America. Clin Microbiol Infect. (2018) 24:755-63. doi: 10.1016/j.cmi.2018.01.018

33. L'Azou M, Moureau A, Zambrano B, Sarti E, Villar L, Wartel TA, et al. Symptomatic dengue in children in 10 Asian and Latin American countries. N Engl J Med. (2016) 374:1155-66. doi: 10.1056/NEJMoa1503877

34. Plennevaux E, Moureau A, Arredondo-García JL, Villar L, Pitisuttithum P, Tran NH, et al. Impact of dengue vaccination on serological diagnosis: insights from phase III dengue vaccine efficacy trials. Clin Infect Dis. (2018) 66:1164-72. doi: 10.1093/cid/cix966

35. Rabaa MA, Wills B, van der Vliet D, Duong Thi Hue K, Dunod C, Zambrano $\mathrm{B}$, et al. Genetic epidemiology of dengue viruses in phase III trials of the CYD tetravalent dengue vaccine and implications for efficacy. Elife. (2017) 6:e24196. doi: 10.7554/eLife.24196.056

36. Harenberg A, Guy B, Saville M, de Montfort A, Jackson N, Bonaparte $\mathrm{M}$, et al. Cytokine profile of children hospitalized with virologicallyconfirmed dengue during two phase III vaccine efficacy trials. PLoS Negl Trop Dis. (2016) 10:e0004830. doi: 10.1371/journal.pntd.00 04830

37. Olivera-Botello G, Coudeville L, Fanouillere K, Guy B, Chambonneau L, Noriega $F$, et al. Tetravalent dengue vaccine reduces symptomatic and asymptomatic dengue virus infections in healthy children and adolescents aged 2-16 years in Asia and Latin America. J Infect Dis. (2016) 214:994-1000. doi: 10.1093/infdis/jiw297

38. Coudeville L, Baurin N, Vergu E. Estimation of parameters related to vaccine efficacy and dengue transmission from two large phase III studies. Vaccine. (2016) 34:6417-25. doi: 10.1016/j.vaccine.2015.11.023

39. Guy B, Jackson N. Dengue vaccine: hypotheses to understand CYD-TDV-induced protection. Nat Rev Microbiol. (2015) 14:45-54. doi: 10.1038/nrmicro.2015.2

40. Gailhardou S, Skipetrova A, Dayan GH, Jezorwski J, Saville M, Van der Vliet $\mathrm{D}$, et al. Safety overview of a recombinant live-attenuated tetravalent dengue vaccine: pooled analysis of data from 18 clinical trials. PLoS Negl Trop Dis. (2016) 10:e0004821. doi: 10.1371/journal.pntd.0004821
41. Vigne C, Dupuy M, Richetin A, Guy B, Jackson N, Bonaparte M, et al. Integrated immunogenicity analysis of a tetravalent dengue vaccine up to $4 \mathrm{y}$ after vaccination. Hum Vaccines Immunother. (2017) 13:2004-16. doi: 10.1080/21645515.2017.1333211

42. Nealon J, Chotpitayasunondh T, Taurel A-F, Chong CK, Frago C, Moureau A, et al. Symptomatic dengue disease in five southeast asian countries: epidemiological evidence from a dengue vaccine trial. PLoS Negl Trop Dis. (2016) 10:e0004918. doi: 10.1371/journal.pntd.0004918

43. Coudeville L, Baurin N, L'Azou M, Guy B. Potential impact of dengue vaccination: insights from two large-scale phase III trials with a tetravalent dengue vaccine. Vaccine. (2016) 34:6426-35. doi: 10.1016/j.vaccine.2016.08.050

44. Melo FIR, Morales JJR, De Los Santos AHM, Rivas E, Vigne C, Noriega F. Immunogenicity and safety of a booster injection of DTap-IPV//Hib (Pentaxim) administered concomitantly with tetravalent dengue vaccine in healthy toddlers 15-18 months of age in Mexico: a randomized trial. Pediatr Infect Dis J. (2017) 36:602-8. doi: 10.1097/INF.0000000000001542

45. Torresi J, Richmond PC, Heron LG, Qiao M, Marjason J, Starr-Spires L, et al. Replication and excretion of the live attenuated tetravalent dengue vaccine CYD-TDV in a flavivirus-naive adult population: assessment of vaccine viremia and virus shedding. J Infect Dis. (2017) 216:834-41. doi: 10.1093/infdis/jix314

46. Torresi J, Richmond PC, Chambonneau L, van der Vliet D, Boaz M, Hutagalung Y, et al. Lot-to-lot consistency of a tetravalent dengue vaccine in healthy adults in Australia: a randomised study. Vaccine. (2015) 33:5127-34. doi: 10.1016/j.vaccine.2015.08.008

47. Henein S, Swanstrom J, Byers AM, Baric R, Bonaparte M, Guy $\mathrm{B}$, et al. Dissecting antibodies induced by a chimeric yellow feverdengue, live-attenuated, tetravalent dengue vaccine (CYD-TDV) in naïve and dengue exposed individuals. J Infect Dis. (2016) 215:351-8. doi: 10.1093/infdis/jiw576

48. Hss A, Koh M, Kee K, Gaik L, Zhou L, Bouckenooghe A, et al. Safety and immunogenicity of a tetravalent dengue vaccine in healthy children aged 2 - 11 years in Malaysia : a randomized, placebo-controlled, phase III study. Vaccine. (2013) 31:5814-21. doi: 10.1016/j.vaccine.2013.10.013

49. Durbin AP, McArthur JH, Marron JA, Blaney JE, Thumar B, Wanionek $\mathrm{K}$, et al. rDEN2/4 $\Delta 30(\mathrm{ME})$, a live attenuated chimeric dengue serotype 2 vaccine, is safe and highly immunogenic in healthy dengue-naïve adults. Hum Vaccin. (2006) 2:255-60. doi: 10.4161/hv.2.6.3494

50. Popper SJ, Strouts FR, Lindow JC, Cheng HK, Montoya M, Balmaseda A, et al. Early transcriptional responses after dengue vaccination mirror the response to natural infection and predict neutralizing antibody titers. J Infect Dis. (2018) 218:1911-21. doi: 10.1093/infdis/jiy434

51. Durbin AP, Kirkpatrick BD, Pierce KK, Carmolli MP, Tibery CM, Grier PL, et al. A 12-month-interval dosing study in adults indicates that a single dose of the national institute of allergy and infectious diseases tetravalent dengue vaccine induces a robust neutralizing antibody response. J Infect Dis. (2016) 214:832-5. doi: 10.1093/infdis/jiw067

52. Kirkpatrick BD, Hynes N, Durbin AP, Walsh MC, Lovchik JM, Whitehead SS, et al. Robust and balanced immune responses to all 4 dengue virus serotypes following administration of a single dose of a live attenuated tetravalent dengue vaccine to healthy, flavivirus-naive adults. J Infect Dis. (2015) 212:702-10. doi: 10.1093/infdis/jiv082

53. Kirkpatrick BD, Whitehead SS, Pierce KK, Tibery CM, Grier PL, Hynes $\mathrm{NA}$, et al. The live attenuated dengue vaccine TV003 elicits complete protection against dengue in a human challenge model. Sci Transl Med. (2016) 8:330ra36. doi: 10.1126/scitranslmed.aaf1517

54. Larsen CP, Whitehead SS, Durbin AP. Dengue human infection models to advance dengue vaccine development. Vaccine. (2015) 33:7075-82. doi: $10.1016 /$ j.vaccine.2015.09.052

55. Bhamarapravati N, Sutee Y. Live attenuated tetravalent dengue vaccine. Vaccine. (2000) 18:44-7. doi: 10.1016/S0264-410X(00)00040-2

56. George SL, Wong MA, Dube TJT, Boroughs KL, Stovall JL, Luy BE, et al. Safety and immunogenicity of a live attenuated tetravalent dengue vaccine candidate in flavivirus-naive adults: a randomized, double-blinded phase 1 clinical trial. J Infect Dis. (2015) 212:1032-41. doi: 10.1093/infdis/jiv179

57. Whitehead SS, Durbin AP, Pierce KK, Elwood D, Mcelvany D, Fraser EA, et al. In a randomized trial, the live attenuated tetravalent dengue vaccine 
TV003 is well- tolerated and highly immunogenic in subjects with flavivirus exposure prior to vaccination. PLoS Negl Trop Dis. (2017) 11:e0005584. doi: 10.1371/journal.pntd.0005584

58. Katzelnick LC, Fonville JM, Gromowski GD, Bustos J, Green A, James SL, et al. HHS public access. J Immigr Minor Health. (2016) 349:1338-43. doi: 10.1126/science.aac5017

59. Durbin AP, Schmidt A, Elwood D, Wanionek KA, Lovchik J, Thumar B, et al. Heterotypic dengue infection with live attenuated monotypic dengue virus vaccines : implications for vaccination of populations in areas where dengue is endemic. J Infect Dis. (2011) 203:327-34. doi: 10.1093/infdis/jiq059

60. Osorio JE, Velez ID, Thomson C, Lopez L, Jimenez A, Haller AA, et al. Safety and immunogenicity of a recombinant live attenuated tetravalent dengue vaccine (DENVax) in flavivirus-naive healthy adults in Colombia: a randomised, placebo-controlled, phase 1 study. Lancet Infect Dis. (2014) 14:830-8. doi: 10.1016/S1473-3099(14)70811-4

61. Sáez-Llorens X, Dato E, Borkowski A, Rauscher M, Vargas M, Wallace $\mathrm{D}$, et al. Immunogenicity and safety of one versus two doses of tetravalent dengue vaccine in healthy children aged 2-17 years in Asia and Latin America: 18-month interim data from a phase 2, randomised, placebo-controlled study. Lancet Infect Dis. (2017) 18:162-70. doi: 10.1016/S1473-3099(17)30632-1

62. Sáez-Llorens X, Tricou V, Yu D, Rivera L, Tuboi S, Garbes P, et al. Safety and immunogenicity of one versus two doses of Takeda's tetravalent dengue vaccine in children in Asia and Latin America: interim results from a phase 2, randomised, placebo-controlled study. Lancet Infect Dis. (2017) 17:615-25. doi: 10.1016/S1473-3099(17)30166-4

63. Jackson LA, Rupp R, Papadimitriou A, Wallace D, Raanan M, Moss KJ. A phase 1 study of safety and immunogenicity following intradermal administration of a tetravalent dengue vaccine candidate. Vaccine. (2018) 36:3976-83. doi: 10.1016/j.vaccine.2018.05.028

64. Swanstrom JA, Henein S, Plante JA, Yount BL, Widman DG, Gallichotte EN, et al. Analyzing the human serum antibody responses to a live attenuated tetravalent dengue vaccine candidate. J Infect Dis. (2018) 217:1932-41. doi: 10.1093/infdis/jiy063

65. Thomas SJ, Eckels KH, Carletti I, De La Barrera R, Dessy F, Fernandez S, et al. A phase II, randomized, safety and immunogenicity study of a re-derived, live-attenuated dengue virus vaccine in healthy adults. Am J Trop Med Hyg. (2013) 88:73-88. doi: 10.4269/ajtmh.2012.12-0361

66. Bauer K, Esquilin IO, Cornier AS, Thomas SJ, Quintero del Rio AI, BertranPasarell J, et al. A phase II, randomized, safety and immunogenicity trial of a re-derived, live-attenuated dengue virus vaccine in healthy children and adults living in puerto rico. Am J Trop Med Hyg. (2015) 93:441-53. doi: 10.4269/ajtmh.14-0625

67. Simasathien S, Thomas SJ, Watanaveeradej V, Nisalak A, Barberousse C, Innis BL, et al. Safety and immunogenicity of a tetravalent live-attenuated dengue vaccine in flavivirus naive children. Am J Trop Med Hyg. (2008) 78:426-33. doi: 10.4269/ajtmh.2008.78.426

68. Thomas SJ, Vaughn DW, Nisalak A, Mammen MP, Watanaveeradej V, Hengprasert S, et al. Safety and immunogenicity of a tetravalent liveattenuated dengue vaccine in flavivirus-naive infants. Am J Trop Med Hyg. (2011) 85:341-51. doi: 10.4269/ajtmh.2011.10-0501

69. Schmidt AC, Lin L, Martinez LJ, Ruck RC, Eckels KH, Collard A, et al. Phase 1 randomized study of a tetravalent dengue purified inactivated vaccine in healthy adults in the United States. Am J Trop Med Hyg. (2017) 96:1325-37. doi: 10.4269/ajtmh.16-0634

70. Diaz C, Lin L, Martinez LJ, Eckels KH, Campos M, Jarman RG, et al. Phase I randomized study of a tetravalent dengue purified inactivated vaccine in healthy adults from puerto rico. Am J Trop Med Hyg. (2018) 98:1435-43. doi: 10.4269/ajtmh.17-0627

71. Danko JR, Kochel T, Teneza-Mora N, Luke TC, Raviprakash K, Sun P, et al. Safety and immunogenicity of a tetravalent dengue DNA vaccine administered with a cationic lipid-based adjuvant in a phase 1 clinical trial. Am J Trop Med Hyg. (2018) 98:849-56. doi: 10.4269/ajtmh.17-0416

72. Manoff SB, George SL, Bett AJ, Yelmene ML, Dhanasekaran G, Eggemeyer L, et al. Preclinical and clinical development of a dengue recombinant subunit vaccine. Vaccine. (2015) 33:7126-34. doi: 10.1016/j.vaccine.2015.09.101

73. Manoff SB, Martin J, Radley D, Coller B-A, Dubey S, Russell AF, et al. Immunogenicity and safety of an investigational tetravalent recombinant subunit vaccine for dengue: results of a Phase I randomized clinical trial in flavivirus-Naïve adults. Hum Vaccin Immunother. (2018) 15:2195-204. doi: 10.1080/21645515.2018.1546523

74. Bray M, Lai CJ. Construction of intertypic chimeric dengue viruses by substitution of structural protein genes. Proc Natl Acad Sci USA. (1991) 88:10342-6. doi: 10.1073/pnas.88.22.10342

75. Chambers TJ, Nestorowicz A, Mason PW, Rice CM. Yellow fever/Japanese encephalitis chimeric viruses: construction and biological properties. J Virol. (1999) 73:3095-101. doi: 10.1128/JVI.73.4.3095-3101.1999

76. Guirakhoo F, Pugachev K, Zhang Z, Myers G, Levenbook I, Draper K, et al. Safety and efficacy of chimeric yellow fever-dengue virus tetravalent vaccine formulations in nonhuman primates. J Virol. (2004) 78:4761-75. doi: 10.1128/JVI.78.9.4761-4775.2004

77. Guirakhoo F, Weltzin R, Chambers TJ, Zhang ZX, Soike K, Ratterree $M$, et al. Recombinant chimeric yellow fever-dengue type 2 virus is immunogenic and protective in nonhuman primates. J Virol. (2000) 74:5477-85. doi: 10.1128/JVI.74.12.5477-5485.2000

78. Guirakhoo F, Arroyo J, Pugachev KV, Miller C, Zhang ZX, Weltzin R, et al. Construction, safety, and immunogenicity in nonhuman primates of a chimeric yellow fever-dengue virus tetravalent vaccine. J Virol. (2001) 75:7290-304. doi: 10.1128/JVI.75.16.7290-7304.2001

79. Gruenberg A, Woo WS, Biedrzycka A, Wright PJ. Partial nucleotide sequence and deduced amino acid sequence of the structural proteins of dengue virus type 2, new Guinea C and PUO-218 strains. J Gen Virol. (1988) 69:1391-8. doi: 10.1099/0022-1317-69-6-1391

80. Brandler S, Brown N, Ermak TH, Mitchell F, Parsons M, Zhang Z, et al. Replication of chimeric yellow fever virus - dengue serotype 1-4 virus vaccine strains in dendritic and hepatic cells. Am J Drop Med Hyg. (2005) 72:74-81. doi: 10.4269/ajtmh.2005.72.74

81. Higgs S, Vanlandingham DL, Klingler KA, Mcelroy KL, Mcgee CE, Harrington L, et al. Growth characteristics of chimerivax-den vaccine viruses in aedes aegypti and aedes albopictus from Thailand. Am J Drop Med Hyg. (2006) 75:986-93. doi: 10.4269/ajtmh.2006.75.986

82. Guirakhoo F, Vaccine DEN, Clinical PI, Kitchener S, Morrison D, Forrat R, et al. Live attenuated chimeric yellow fever dengue type 2 (ChimeriVax TM ND SC RIB. Hum Vaccine. (2006) 2:60-7. doi: 10.4161/hv.2.2.2555

83. Poo J, Zambrano B, Galan F, Dayan GH, Forrat R, Lang J. Liveattenuated tetravalent dengue vaccine in dengue-naïve children, adolescents, and adults in Mexico city. Pediatr Infect Dis J. (2011) 30:e9-e17. doi: 10.1097/INF.0b013e3181fe05af

84. Morrison D, Billings CW, Forrat R, Legg TJ, Lang J, Yoksan S. A novel tetravalent dengue vaccine is well tolerated and immunogenic against all 4 serotypes in flavivirus -naive adults. J Infect Dis. (2010) 201:370-7. doi: $10.1086 / 649916$

85. Capeding RZ, Luna IA, Bomasang E, Lupisan S, Lang J, Forrat R, et al. Live-attenuated, tetravalent dengue vaccine in children, adolescents and adults in a dengue endemic country: randomized controlled phase I trial in the philippines. Vaccine. (2011) 29:3863-72. doi: 10.1016/j.vaccine.2011. 03.057

86. Wilder-smith A, Hombach J, Ferguson N, Selgelid M, Brien KO, Vannice K, et al. Personal view deliberations of the strategic advisory group of experts on immunization on the use of CYD-TDV dengue vaccine. Lancet Infect Dis. (2018) 19:e31-8. doi: 10.1016/S1473-3099(18)30494-8

87. Guy B, Nougarede N, Begue S, Sanchez V, Souag N, Carre M, et al. Cell-mediated immunity induced by chimeric tetravalent dengue vaccine in naive or flavivirus-primed subjects. Vaccine. (2008) 26:5712-21. doi: 10.1016/j.vaccine.2008.08.019

88. Godói IP, Lemos LLP, De Araújo VE, Bonoto BC, Godman B, Guerra Júnior AA. CYD-TDV dengue vaccine: systematic review and meta-analysis of efficacy, immunogenicity and safety. J Comp Eff Res. (2017) 6:165-80. doi: 10.2217/cer-2016-0045

89. Men R, Bray M, Clark D, Chanock RM, Lai CJ. Dengue type 4 virus mutants containing deletions in the $3^{\prime}$ noncoding region of the RNA genome: analysis of growth restriction in cell culture and altered viremia pattern and immunogenicity in rhesus monkeys. J Virol. (1996) 70:3930-7. doi: 10.1128/JVI.70.6.3930-3937.1996

90. Troyer JM, Durbin AP, Strickman D, Hanley KA, Karron RA, Murphy BR, et al. A live attenuated recombinant dengue- 4 virus vaccine candidate with 
restricted capacity for dissemination in mosquitoes and lack of transmission from vaccinees to mosquitoes. Am J Trop Med Hyg. (2001) 65:414-19. doi: 10.4269/ajtmh.2001.65.414

91. Durbin AP, Karron RA, Sun W, Vaughn DW, Reynolds MJ, Perreault JR, et al. Attenuation and immunogenicity in humans of a live dengue virus type- 4 vaccine candidate with a 30 nucleotide deletion in its 3 '-untranslated region. Am J Trop Med Hyg. (2001) 65:405-13. doi: 10.4269/ajtmh.2001.65.405

92. Durbin AP, Whitehead SS, McArthur J, Perreault JR, Blaney JE Jr, Thumar B, et al. $\operatorname{rDEN} 4 \Delta 30$, a live attenuated dengue virus type 4 vaccine candidate, is safe, immunogenic, and highly infectious in healthy adult volunteers. J Infect Dis. (2005) 191:710-8. doi: 10.1086/427780

93. Whitehead SS, Falgout B, Hanley KA, Blaney JE, Markoff L, Murphy BR. A live, attenuated dengue virus type 1 vaccine candidate with a 30-nucleotide deletion in the 3' untranslated region is highly attenuated and immunogenic in monkeys. J Virol. (2003) 77:1653-7. doi: 10.1128/JVI.77.2.1653-1657.2003

94. Sun W, Edelman R, Kanesa-Thasan N, Eckels KH, Putnak JR, King AD, et al. Vaccination of human volunteers with monovalent and tetravalent liveattenuated dengue vaccine candidates. Am J Trop Med Hyg. (2003) 69:24-31. doi: 10.4269/ajtmh.2003.69.6_suppl.0690024

95. Durbin AP, McArthur J, Marron JA, Blaney JE, Thumar B, Wanionek K, et al. The live attenuated dengue serotype 1 vaccine $\operatorname{rDEN} 1 \triangle 30$ is safe and highly immunogenic in healthy adult volunteers. Hum Vaccin. (2006) 2:167-73. doi: $10.4161 /$ hv.2.4.2944

96. Blaney JE, Durbin AP, Murphy BR, Whitehead SS. Development of a live attenuated dengue virus vaccine using reverse genetics. Viral Immunol. (2006) 19:10-32. doi: 10.1089/vim.2006.19.10

97. Whitehead SS, Hanley KA, Blaney JE, Gilmore LE, Elkins WR, Murphy BR. Substitution of the structural genes of dengue virus type 4 with those of type 2 results in chimeric vaccine candidates which are attenuated for mosquitoes, mice, and rhesus monkeys. Vaccine. (2003) 21:4307-16. doi: $10.1016 / \mathrm{S} 0264-410 \mathrm{X}(03) 00488-2$

98. Blaney JE, Whitehead SS, Hanley KA, Murphy BR, Hanson CT, Firestone C-Y. Genetically modified, live attenuated dengue virus type 3 vaccine candidates. Am J Trop Med Hyg. (2004) 71:811-21. doi: 10.4269/ajtmh.2004.71.811

99. Durbin AP, Kirkpatrick BD, Pierce KK, Schmidt AC, Whitehead SS. Development and clinical evaluation of multiple investigational monovalent DENV vaccines to identify components for inclusion in a live attenuated tetravalent DENV vaccine. Vaccine. (2011) 29:7242-50. doi: 10.1016/j.vaccine.2011.07.023

100. Blaney JE, Sathe NS, Goddard L, Hanson CT, Romero TA, Hanley KA, et al. Dengue virus type 3 vaccine candidates generated by introduction of deletions in the $3^{\prime}$ untranslated region $\left(3^{\prime}\right.$-UTR) or by exchange of the DENV-3 $3^{\prime}$-UTR with that of DENV-4. Vaccine. (2008) 26:817-28. doi: 10.1016/j.vaccine.2007.11.082

101. Lindow JC, Durbin AP, Whitehead SS, Pierce KK, Carmolli MP, Kirkpatrick BD. Vaccination of volunteers with low-dose, live-attenuated, dengue viruses leads to serotype-specific immunologic and virologic profiles. Vaccine. (2013) 31:3347-52. doi: 10.1016/j.vaccine.2013.05.075

102. Durbin AP, Kirkpatrick BD, Pierce KK, Elwood D, Larsson CJ, Lindow JC, et al. A single dose of any of four different live attenuated tetravalent dengue vaccines is safe and immunogenic in flavivirus-naive adults: a randomized, double-blind clinical trial. J Infect Dis. (2013) 207:957-65. doi: 10.1093/infdis/jis936

103. Blaney JE, Hanson CT, Hanley KA, Murphy BR, Whitehead SS. Vaccine candidates derived from a novel infectious cDNA clone of an American genotype dengue virus type 2. BMC Infect Dis. (2004) 4:1-10. doi: 10.1186/1471-2334-4-39

104. Rupp R, Santangelo JD, Stinchcomb DT, Raanan M, Gordon GS, Wallace D, et al. Safety and immunogenicity of different doses and schedules of a live attenuated tetravalent dengue vaccine (TDV) in healthy adults: a Phase 1b randomized study. Vaccine. (2015) 33:6351-9. doi: 10.1016/j.vaccine.2015.09.008

105. Butrapet S, Huang CY, Pierro DJ, Bhamarapravati N, Gubler DJ, Kinney RM. Attenuation markers of a candidate dengue type 2 vaccine virus, strain 16681 (PDK-53), are defined by mutations in the 5' noncoding region and nonstructural proteins 1 and 3. J Virol. (2000) 74:3011-9. doi: 10.1128/JVI.74.7.3011-3019.2000
106. Bhamarapravati N, Chayaniyayothin T, Angsubphakorn S. Immunization with a live attenuated dengue-2-virus logical and biological responses in adult volunteers. Bull World Health Organ. (1987) 65:189-95.

107. Kinney RM, Butrapet S, Chang G-JJ, Tsuchiya KR, Roehrig JT, Bhamarapravati $\mathrm{N}$, et al. Construction of infectious cDNA clones for dengue 2 virus: strain 16681 and its attenuated vaccine derivative, strain PDK-53. Virology. (1997) 230:300-8. doi: 10.1006/viro.1997.8500

108. Butrapet S, Huang CYH, Pierro DJ, Bhamarapravati N, Gubler DJ, Kinney RM. Replication of the primary dog kidney-53 dengue 2 virus vaccine candidate in aedes aegypti is modulated by a mutation in the $5^{\prime}$ untranslated region and amino acid substitutions in nonstructural proteins 1 and 3. Vector Borne Zoonotic Dis. (2000) 11:683-9. doi: 10.1089/vbz.2010.0150

109. Halstead SB, Marchette NJ. Biologic properties of dengue viruses following serial passage in primary dog kidney cells: studies at the university of Hawaii. Am J Trop Med Hyg. (2003) 69:5-11. doi: 10.4269/ajtmh.2003.69.6_suppl.0690005

110. Kitchener S, Nissen M, Nasveld P, Forrat R, Yoksan S, Lang J, et al. Immunogenicity and safety of two live-attenuated tetravalent dengue vaccine formulations in healthy Australian adults. Vaccine. (2006) 24:1238-41. doi: 10.1016/j.vaccine.2005.09.029

111. Vaughn DW, Hoke CH, Yoksan S, LaChance R, Innis BL, Rice RM, et al. Testing of a dengue 2 live-attenuated vaccine (strain 16681 PDK 53) in ten American volunteers. Vaccine. (1996) 14:329-36. doi: 10.1016/0264-410X(95)00167-Y

112. Huang CY-H, Hunt AR, Kinney RM, Gubler DJ, Bhamarapravati N, Pierro DJ, et al. Chimeric dengue type 2 (vaccine strain PDK-53)/dengue type 1 virus as a potential candidate dengue type 1 virus vaccine. J Virol. (2000) 74:3020-8. doi: 10.1128/JVI.74.7.3020-3028.2000

113. Huang CY-H, Butrapet S, Tsuchiya KR, Bhamarapravati N, Gubler DJ, Kinney RM. Dengue 2 PDK-53 virus as a chimeric carrier for tetravalent dengue vaccine development. J Virol. (2003) 77:11436-47. doi: 10.1128/JVI.77.21.11436-11447.2003

114. Huang CY-H, Kalanidhi AP, Silengo SJ, Brault AC, Arguello JJ, Boroughs KL, et al. Genetic and phenotypic characterization of manufacturing seeds for a tetravalent dengue vaccine (DENVax). PLoS Negl Trop Dis. (2013) 7:e2243. doi: 10.1371/journal.pntd.0002243

115. Osorio JE, Wallace D, Stinchcomb DT. A recombinant, chimeric tetravalent dengue vaccine candidate based on a dengue virus serotype 2 backbone. Expert Rev Vaccines. (2016) 15:497-508. doi: 10.1586/14760584.2016.1128328

116. Brewoo JN, Kinney RM, Powell TD, Arguello JJ, Silengo SJ, Partidos CD, et al. Immunogenicity and efficacy of chimeric dengue vaccine (DENVax) formulations in interferon-deficient AG129 mice. Vaccine. (2012) 30:151320. doi: 10.1016/j.vaccine.2011.11.072

117. Osorio JE, Brewoo JN, Silengo SJ, Arguello J, Moldovan IR, TaryLehmann $M$, et al. Efficacy of a tetravalent chimeric dengue vaccine (DENVax) in cynomolgus macaques. Am J Trop Med Hyg. (2011) 84:978-87. doi: 10.4269/ajtmh.2011.10-0592

118. Biswal S, Reynales H, Saez-Llorens X, Lopez P, Borja-Tabora C, Kosalaraksa $P$, et al. Efficacy of a tetravalent dengue vaccine in healthy children and adolescents. N Engl J Med. (2019) 381:2009-19. doi: 10.1056/NEJMoa1903869

119. Eckels KH, Innis BL, Dubois DR, Hoke CH, Henchal EA, Putnak R, et al. Modification of dengue virus strains by passage in primary dog kidney cells: preparation of candidate vaccines and immunization of monkeys. Am J Trop Med Hyg. (2013) 69:12-16. doi: 10.4269/ajtmh.2003.69.12

120. Edelman R, Wasserman SS, Bodison SA, Putnak RJ, Eckels KH, Tang D, et al. Phase I trial of 16 formulations of a tetravalent live-attenuated dengue vaccine. Am J Trop Med Hyg. (2003) 69:48-60. doi: 10.4269/ajtmh.200 3.69 .48

121. Sun W, Cunningham D, Wasserman SS, Perry J, Putnak JR, Eckels KH, et al. Phase 2 clinical trial of three formulations of tetravalent live-attenuated dengue vaccine in flavivirus-naïve adults. Hum Vaccin. (2009) 5:33-40. doi: 10.4161/hv.5.1.6348

122. Tournay E, Kerdpanich A, Eckels KH, Dessy F, Innis BL, De La Barrerra R, et al. Safety and immunogenicity of a rederived, live-attenuated dengue virus vaccine in healthy adults living in Thailand: a randomized trial. Am J Trop Med Hyg. (2014) 91:119-28. doi: 10.4269/ajtmh.13-0452 
123. Putnak R, Barvir DA, Burrous JM, Dubois DR, D’Andrea VM, Hoke $\mathrm{CH}$, et al. Development of a purified, inactivated, dengue-2 virus vaccine prototype in vero cells: immunogenicity and protection in mice and rhesus monkeys. J Infect Dis. (1996) 174:1176-84. doi: 10.1093/infdis/174.6.1176

124. Robert Putnak J, Coller B-A, Voss G, Vaughn DW, Clements D, Peters I, et al. An evaluation of dengue type-2 inactivated, recombinant subunit, and liveattenuated vaccine candidates in the rhesus macaque model. Vaccine. (2005) 23:4442-52. doi: 10.1016/j.vaccine.2005.03.042

125. Simmons M, Burgess T, Lynch J, Putnak R. Protection against dengue virus by non-replicating and live attenuated vaccines used together in a prime boost vaccination strategy. Virology. (2010) 396:280-8. doi: 10.1016/j.virol.2009.10.023

126. Fernandez S, Thomas SJ, De La Barrera R, Im-Erbsin R, Jarman RG, Baras B, et al. An adjuvanted, tetravalent dengue virus purified inactivated vaccine candidate induces long-lasting and protective antibody responses against dengue challenge in rhesus macaques. Am J Trop Med Hyg. (2015) 92:698708. doi: 10.4269/ajtmh.14-0268

127. Martinez LJ, Lin L, Blaylock JM, Lyons AG, Bauer KM, De La Barrera R, et al. Safety and immunogenicity of a dengue virus serotype-1 purifiedinactivated vaccine: results of a phase 1 clinical trial. Am J Trop Med Hyg. (2015) 93:454-60. doi: 10.4269/ajtmh.14-0819

128. Didierlaurent AM, Laupèze B, Di Pasquale A, Hergli N, Collignon C, Garçon N. Adjuvant system AS01: helping to overcome the challenges of modern vaccines. Expert Rev Vaccines. (2017) 16:55-63. doi: 10.1080/14760584.2016.1213632

129. Garçon N, Van Mechelen M. Recent clinical experience with vaccines using MPL- and QS-21-containing adjuvant systems. Expert Rev Vaccines. (2011) 10:471-86. doi: 10.1586/erv.11.29

130. Borges MB, Marchevsky RS, Pereira RC, Mendes S, Gustavo L, Mendes A, et al. Detection of post-vaccination enhanced dengue virus infection in macaques : an improved model for early assessment of dengue vaccines. PLoS Pathog. (2019) 15:e1007721. doi: 10.1371/journal.ppat.1007721

131. Porter KR, Ewing D, Chen L, Wu S-J, Hayes CG, Ferrari M, et al. Immunogenicity and protective efficacy of a vaxfectin-adjuvanted tetravalent dengue DNA vaccine. Vaccine. (2012) 30:336-41. doi: $10.1016 /$ j.vaccine.2011.10.085

132. Raviprakash K, Luke T, Doukas J, Danko J, Porter K, Burgess T, et al. A dengue DNA vaccine formulated with Vaxfectin ${ }^{\circledR}$ is well tolerated, and elicits strong neutralizing antibody responses to all four dengue serotypes in New Zealand white rabbits. Hum Vaccin Immunother. (2012) 8:1764-8. doi: $10.4161 /$ hv.21806

133. Raviprakash K, Kochel TJ, Ewing D, Simmons M, Phillips I, Hayes CG, et al. Immunogenicity of dengue virus type 1 DNA vaccines expressing truncated and full length envelope protein. Vaccine. (2000) 18:2426-34. doi: 10.1016/S0264-410X(99)00570-8

134. Kochel T, Wu SJ, Raviprakash K, Hobart P, Hoffman S, Porter $\mathrm{K}$, et al. Inoculation of plasmids expressing the dengue-2 envelope gene elicit neutralizing antibodies in mice. Vaccine. (1997) 15:547-52. doi: 10.1016/S0264-410X(97)00215-6

135. Porter KR, Kochel TJ, Wu SJ, Raviprakash K, Phillips I, Hayes CG. Protective efficacy of a dengue 2 DNA vaccine in mice and the effect of CpG immunostimulatory motifs on antibody responses. Arch Virol. (1998) 143:997-1003. doi: 10.1007/s007050050348

136. Lu Y, Raviprakash K, Leao IC, Chikhlikar PR, Ewing D, Anwar A, et al. Dengue 2 PreM-E/LAMP chimera targeted to the MHC class II compartment elicits long-lasting neutralizing antibodies. Vaccine. (2003) 21:2178-89. doi: 10.1016/S0264-410X(03)00009-4

137. Blair PJ, Kochel TJ, Raviprakash K, Guevara C, Salazar M, Wu S-J, et al. Evaluation of immunity and protective efficacy of a dengue3 pre-membrane and envelope DNA vaccine in Aotus nancymae monkeys. Vaccine. (2006) 24:1427-32. doi: 10.1016/j.vaccine.2005. 09.032

138. Raviprakash K, Apt D, Brinkman A, Skinner C, Yang S, Dawes G, et al. A chimeric tetravalent dengue DNA vaccine elicits neutralizing antibody to all four virus serotypes in rhesus macaques. Virology. (2006) 353:166-73. doi: 10.1016/j.virol.2006.05.005

139. Clements DE, Coller B-AG, Lieberman MM, Ogata S, Wang G, Harada $\mathrm{KE}$, et al. Development of a recombinant tetravalent dengue virus vaccine: immunogenicity and efficacy studies in mice and monkeys. Vaccine. (2010) 28:2705-15. doi: 10.1016/j.vaccine.2010.01.022

140. Eckels KH, Brandt WE, Harrison VR, McCown JM, Russell PK. Isolation of a temperature-sensitive dengue-2 virus under conditions suitable for vaccine development. Infect Immun. (1976) 14:1221-7. doi: 10.1128/IAI.14.5.1221-1227.1976

141. Hahn YS, Galler R, Hunkapiller T, Dalrymple JM, Strauss JH, Strauss EG. Nucleotide sequence of dengue 2 RNA and comparison of the encoded proteins with those of other flaviviruses. Virology. (1988) 162:167-80. doi: 10.1016/0042-6822(88)90406-0

142. Osatomi K, Fuke I, Tsuru D, Shiba T, Sakaki Y, Sumiyoshi H. Nucleotide sequence of dengue type 3 virus genomic RNA encoding viral structural proteins. Virus Genes. (1988) 2:99-108. doi: 10.1007/BF005 69739

143. Zhao B, Mackow E, Buckler-White A, Markoff L, Chanock RM, Lai CJ, et al. Cloning full-length dengue type 4 viral DNA sequences: analysis of genes coding for structural proteins. Virology. (1986) 155:77-88. doi: 10.1016/0042-6822(86)90169-8

144. Govindarajan D, Meschino S, Guan L, Clements DE, ter Meulen $\mathrm{JH}$, Casimiro DR, et al. Preclinical development of a dengue tetravalent recombinant subunit vaccine: immunogenicity and protective efficacy in nonhuman primates. Vaccine. (2015) 33:4105-16. doi: 10.1016/j.vaccine.2015.06.067

145. Dos Santos Franco L, Gushi LT, Luiz WB, Amorim JH. Seeking flavivirus cross-protective immunity. Front Immunol. (2019) 10:2260. doi: 10.3389/fimmu.2019.02260

146. Weiskopf D, Angelo MA, Bangs DJ, Sidney J, Paul S, Peters B, et al. The human CD8 $+\mathrm{T}$ cell responses induced by a live attenuated tetravalent dengue vaccine are directed against highly conserved epitopes. J Virol. (2015) 89:120-8. doi: 10.1128/JVI.02129-14

Conflict of Interest: The authors declare that the research was conducted in the absence of any commercial or financial relationships that could be construed as a potential conflict of interest.

Copyright (c) 2020 Pinheiro-Michelsen, Souza, Santana, da Silva, Mendez, Luiz and Amorim. This is an open-access article distributed under the terms of the Creative Commons Attribution License (CC BY). The use, distribution or reproduction in other forums is permitted, provided the original author(s) and the copyright owner(s) are credited and that the original publication in this journal is cited, in accordance with accepted academic practice. No use, distribution or reproduction is permitted which does not comply with these terms. 